University of Nebraska - Lincoln

DigitalCommons@University of Nebraska - Lincoln

Zea E-Books

Zea E-Books

4-14-2021

\title{
Lydie Salvayre, maintenant même
}

Warren Motte

Lydie Salvayre

Bernard Wallet

David Lopez

Marie Cosnay

See next page for additional authors

Follow this and additional works at: https://digitalcommons.unl.edu/zeabook

Part of the Comparative Literature Commons, European Languages and Societies Commons, and the French and Francophone Literature Commons

This Book is brought to you for free and open access by the Zea E-Books at DigitalCommons@University of Nebraska - Lincoln. It has been accepted for inclusion in Zea E-Books by an authorized administrator of DigitalCommons@University of Nebraska - Lincoln. 


\section{Authors}

Warren Motte, Lydie Salvayre, Bernard Wallet, David Lopez, Marie Cosnay, Mahir Guven, and Stéphane Bikialo 



\section{Sommaire}

Warren Motte, «Dans le vif du vivant»

Lydie Salvayre et Warren Motte, «Une conversation avec Lydie Salvayre»

Lydie Salvayre, «Deux artistes»

Lydie Salvayre, «Projet en cours»

Lydie Salvayre, «Quatre photos»

Bernard Wallet, «Lydie Salvayre, écrivain baroque'n'roll»

David Lopez, «Almuerz»

Marie Cosnay, «Diamant brut»

Mahir Guven, «À propos de Lydie Salvayre»

Stéphane Bikialo, «Éloge de la fuite»

«Ouvrages de Lydie Salvayre»

ISBN 978-1-60962-198-8 ebook

doi: 10.32873/unl.dc.zea.1280

Cover photo: (C) Martine Heissat

Zea Books

Lincoln, Nebraska

Nebrashat

Lincoln 


\section{Lydie Salvayre, maintenant même}

Textes réunis par Warren Motte 
Copyright (c 2021 Lydie Salvayre, Warren Motte, Bernard Wallet, David Lopez, Marie Cosnay, Mahir Guven, \& Stéphane Bikialo.

ISBN: 978-1-60962-197-1 paperback

ISBN: 978-1-60962-198-8 ebook

doi: 10.32873/unl.dc.zea.1280

Composé de types Merriweather et Cabin.

Les Zea Books sont publiés par les bibliothèques de l'Université du Nebraska-Lincoln.

Édition électronique (pdf) disponible en ligne sur https://digitalcommons.unl.edu/zeabook/

Édition imprimée disponible sur Lulu.com à https://www.lulu.com/spotlight/unllib

UNL ne fait aucune discrimination fondée sur un statut protégé. S'il vous plaît allez à https://www.unl.edu/equity/notice-nondiscrimination 


\section{Sommaire}

Warren Motte, «Dans le vif du vivant» . . . . . . . . 5

Lydie Salvayre et Warren Motte, «Une conversation avec Lydie Salvayre» . . . . . . . . . . . . 23

Lydie Salvayre, «Deux artistes» . . . . . . . . 40

Lydie Salvayre, «Projet en cours» . . . . . . . . . 47

Lydie Salvayre, «Quatre photos». . . . . . . . . . 50

Bernard Wallet, «Lydie Salvayre, écrivain baroque'n'roll» . . . . . . . . . . . . . . 54

David Lopez, «Almuerz». . . . . . . . . . . . 66

Marie Cosnay, «Diamant brut» . . . . . . . . . 75

Mahir Guven, «À propos de Lydie Salvayre» . . . . 81

Stéphane Bikialo, «Éloge de la fuite». . . . . . . . 91

«Ouvrages de Lydie Salvayre» . . . . . . . . . . . 102 



\section{Warren Motte}

\section{Dans le vif du vivant}

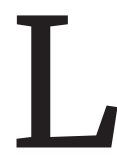

es livres de Lydie Salvayre sont implacables, obsessionnels, insistants. Ils débordent de gens qui hurlent, qui fustigent, qui accusent, des gens qui estiment qu'il y a quelque chose qui ne va pas dans l'ordre accepté des choses, et qui ne relâcheront pas. Salvayre dit « Non! » de manière superbement éloquente ; elle refuse d'approuver la sagesse reçue; elle pense que tout mérite d'être interrogé. À notre époque si houleuse et incertaine, ces livres sont vivifiants, des vaccins puissants contre les foutaises outrageuses qui nous bombardent de façon quotidienne, constante. Son écriture se situe dans le vif du vivant, pour emprunter une phrase de Salvayre elle-même, phrase dont elle se sert pour décrire la façon d'être de Pablo Picasso. Vif comme vital, le site où tous les sens sont activés, où rien ne passe inaperçu, où notre attention se focalise et où le jeu de la vie se déroule de manière débridée. Vif comme rapide, ardent, sensible, intense, réactif, aigu. Vif comme listo aussi, ce mot espagnol qui désigne l'empressement, mais qui connote également l'alacrité intellectuelle, l'habilité, la volonté d'agir immédiatement. Ce mot de la langue maternelle de Salvayre lui va comme un gant, parce qu'elle est surtout lista : rapide à réagir, rapide à comprendre, rapide à s'engager avec nous, rapide à demander notre engagement avec elle.

Published in Lydie Salvayre, maintenant même, ed. Warren Motte (Lincoln, NE : Zea Books, 2021). doi: 10.32873/unl.dc.zea.1281 
Lydie Salvayre n'est pas née dans la littérature française ; au contraire, elle y est venue selon ses propres termes. Ses parents étaient des républicains espagnols qui avaient gagné la France en 1939, à la fin de la Guerre Civile, lorsque les dernières forces républicaines cédaient sous l'assaut des fascistes. Son père était andalou et communiste ; sa mère catalane avait été fortement impressionnée par l'anarchisme actif et pragmatique à Barcelone. Ils se sont rencontrés dans le camp d'internement notoire d'Argelès. Née en 1948 sous le nom de Lydie Arjona, Salvayre a grandi dans une communauté de réfugiés près de Toulouse, où selon ses propres dires le débat politique était son pain quotidien, et le souvenir de la Guerre Civile demeurait frais, bien après sa fin. Jusqu'à sa rentrée dans l'école primaire, où elle a été obligée d'apprendre le français, elle ne parlait que l'espagnol. Elle a commencé à lire avidement au lycée, et elle a décroché une licence de littérature à l'université de Toulouse. Ayant découvert la psychanalyse, elle s'est inscrite à la faculté de médecine, où elle a obtenu un autre diplôme. Elle est devenue psychiatre, se spécialisant éventuellement dans la psychiatrie pédagogique. Elle a publié son premier roman, La Déclaration, en 1990.

Depuis lors, elle a écrit une vingtaine de livres, et elle s'est fait une place sur l'horizon de la littérature française contemporaine. Parmi les prix qu'elle a reçus, on citera le Goncourt décerné en 2014 à Pas pleurer, roman qui reprend l'éveil politique, culturel et sexuel de sa mère, adolescente à l'époque découvrant Barcelone en pleine révolution. Le Goncourt est sans doute le plus prestigieux parmi les nombreux prix littéraires français, et cela fournit une vaste considération à l'auteur qui le reçoit, car il assure quelque chose comme un demi-million de ventes, ainsi qu'un attention médiatique énorme. Cependant, malgré toute cette 
reconnaissance, on a l'impression que Salvayre est moins confortable sur un piédestal que dans les marges, dans une posture d'interrogation, exerçant une ironie finement affûtée afin de mettre en question la pensée conventionnelle et les canons qui l'articulent. Ceux qui la lisent attentivement noteront un scepticisme à l'égard des établissements de différentes sortes - y compris l'établissement littéraire-ainsi qu'une affirmation de sa propre particularité, des effets qui parcourent son œuvre depuis le début jusqu'au présent.

J'aimerais survoler cet œuvre très rapidement, à l'intention de ceux qui ne le connaissent pas, ou peu. Ce faisant, j'essayerai de mettre en lumière certains traits clefs de son écriture, ceux qui me semblent signifiants. L'importance qu'elle accorde à la voix, par exemple, sa façon de traduire la voix dans ses romans, sa manière d'écouter des voix très variées, sa manière de nous encourager à écoutermême si nous sommes les seuls qui écoutons. Je suis impressionné aussi par sa façon de penser le langage, l'imaginant en termes relativistes, comme tout individu bilingue doit le faire, plutôt qu'en termes absolus, comme les gens monolingues. Son emploi de l'ironie mérite notre attention, parce que l'ironie est un outil dangereux qui peut se retourner contre la personne qui la déploie, pour peu que la vigilance de cette personne se relâche. Il convient aussi de souligner la manière dont Salvayre met la société française en procès dans ses livres, obligeant son lecteur à considérer certaines caractéristiques de cette société que la littérature plus conventionnelle passe sous silence. Mais ce qui m'intéresse le plus, peut-être, c'est l'esprit anticonformiste qui anime l'écriture de Salvayre. Elle pratique ce que Ross Chambers appelle « conduite oppositionnelle », élaborant des stratégies de résistance qui exploitent les points faibles 
des structures du pouvoir, retournant le pouvoir contre luimême par un geste radicalement critique.

Tous ces traits figurent dans La Déclaration (1990). Comme beaucoup de ses romans, c'est un texte monologique où l'unique voix parle implacablement. Le protagoniste est un homme abandonné par son épouse, et qui se sent absolument seul dans le monde. Personne ne l'écoute, il se plaint, personne ne se soucie de lui, les gens le fuient comme si sa solitude était contagieuse. Il se dégoûte de lui-même et de sa situation misérable dans la vie, la force du réel l'écrase, il est incapable d'humour, d'aise ou de grâce. Il soupçonne que la folie l'attend. Bref, c'est un individu en crise-et c'est cela, plus que toute autre chose, qui intéresse Salvayre. Il en est venu au point où la seule chose à faire, c'est de hurler son désespoir. De toute évidence, Salvayre estime qu'un tel hurlement signifie pleinement, et que cela mérite notre attention, aussi difficile que cela peut être de l'écouter.

Salvayre nous offre une invitation similaire dans La Vie commune (1991). La narratrice du roman s'appelle Suzanne, une femme mûre qui travaille comme secrétaire dans une entreprise. Elle nourrit une haine prononcée pour une collègue nouvellement arrivée. Tout de cette collègue agace $\mathrm{Su}-$ zanne : elle fume, elle mâche du chewing-gum, et la profondeur de son hypocrisie n'a d'égal que la profondeur de son décolleté. Suzanne brûle d'une rage qui se retourne contre elle-même de façon inéluctable, car comme le narrateur de La Déclaration, elle ne peut rien voir en dehors de cette rage. La Vie commune est une parabole d'obsession qui trace la manière dont les irritations ordinaires, intériorisées et suppurantes, peuvent assumer des proportions massives dans l'esprit de quelqu'un qui cherche la catastrophe, le désastre, le drame-qui cherche n'importe quoi pour fournir un peu de couleur à une existence absolument monochrome. 
Dans La Médaille (1993) Salvayre donne libre cours à son penchant pour l'ironie. Elle mise sur la voix encore une fois, mais ici plusieurs voix rentrent en jeu, plutôt qu'une seule. L'occasion est une cérémonie de fin d'année dans une usine, où les patrons font l'éloge de ceux parmi les ouvriers désignés comme spécialement méritants, et ces ouvriers rendent la pareille, exprimant leur gratitude face à cette reconnaissance inespérée. L'économie discursive est déséquilibrée en faveur des patrons, comme on pourrait s'y attendre. D'une part, les patrons ont l'habitude d'employer le langage comme une technique de pouvoir et de contrôle. D'autre part, ils étouffent rapidement toute tentative de la part des ouvriers à employer le langage de façon autre que purement phatique. On apprend (par inférence, pour la plupart) que des perturbations couvent au sein de l'usine : certains ouvriers sont désaffectés, certains des lauréats sont des indicateurs, la grève se profile. Les patrons savent qu'il faut que leurs mots comptent, et donc ils les déploient comme des sabres. Le langage dans ce roman est lacérant : il coupe et il tranche.

Un autre bavard occupe le centre de la scène dans La Puissance des mouches (1995). Il est gardien de musée à PortRoyal-des-Champs, l'abbaye à côté de Paris où Blaise Pascal s'était retiré. Le gardien de musée est un homme qui a beaucoup souffert : c'est le fils d'un père brutal, sa femme l'a quitté, son patron le maltraite cruellement. Quelque part en chemin il a tué quelqu'un, mais il nous faudra attendre la fin du roman pour savoir qui. La prison où il vit maintenant, et d'où il nous parle, sert simplement à matérialiser les conditions carcérales de sa vie d'avant son inculpation. Le monde que Salvayre construit dans ce roman est exceptionnellement exigu. Il n'y a pas de sortie, pas de place pour se retourner ; c'est un espace claustral et angoissant 
où les possibilités sont extrêmement contraintes, réduites et inévitables.

Située dans la banlieue ouvrière de Paris, La Compagnie des spectres (1997) est l'histoire d'une femme qui s'appelle Rose, de sa fille de dix-huit ans, Louisiane, et d'un huissier nommé Maître Échinard, venu les expulser de leur appartement. À travers Rose, Salvayre engage l'historique et la politique plus largement que dans ses romans précédents, parce que Rose vit simultanément dans le présent et dans le passé-ce passé étant les années de l'Occupation allemande, pendant lesquelles sont frère s'était fait assassiner par la milice française collaborationniste. Rose est persuadée que Maître Échinard a été envoyé par Joseph Darnand (le chef de la milice, traduit en justice et exécuté pour ses crimes peu après la Libération), et rien ne peut l'en dissuader. Elle est folle, certainement, mais sa folie sert à mettre en évidence certaines iniquités de la société française qui n'ont pas beaucoup changé dans le demi-siècle depuis la fin de la guerre.

Dans Quelques Conseils utiles aux élèves huissiers (1997) Maître Échinard revient, cette fois parlant de sa propre voix, et à pleine gorge. Il s'adresse à une salle bondée d'apprentis, décrivant les situations qu'ils risquent de rencontrer une fois qu'ils seront pleinement en possession de leurs titres professionnels. Il évoque sa rencontre avec Rose et Louisiane comme étude de cas exemplaire, mais son récit est bien différent de celui que Salvayre nous offre dans La Compagnie des spectres. Hélas, ses élèves sont terriblement obtus. Ils n'ont jamais entendu parler de Darnand, ils ne savent pas ce que cela veut dire, le mot paranoïa. Maître Échinard est donc obligé de procéder de manière très lente et judicieuse s'il espère partager une portion, même infime, de sa sagesse avec ces élèves. Mais étant donné le métier qu'il exerce, il a naturellement l'habitude des gens aussi stupides qu'insipides. 
Comme dans certains de ses autres textes, Lydie Salvayre nous invite ici à lire contre le grain du discours de son narrateur, afin d'apprécier des réalités qu'il est lui-même incapable de reconnaître.

Dans La Conférence de Cintegabelle (1999) un homme fait une conférence sur les vertus de la conversation devant un public d'amis et voisins dans un village pyrénéen. Son épouse, apprend-on, est morte il y a deux mois - et nous apprendrons beaucoup plus à son sujet au cours du récit, mais seulement par bribes. La conversation est un art, selon le conférencier, un art éminemment français. Pourtant, il craint le déclin de cet art, et par conséquent le déclin du pays où il trouve son expression la plus noble. Ce qu'il propose aux âmes intrépides de Cintegabelle venues l'écouter, ce n'est rien de moins qu'un projet de revitalisation conversationnelle, et donc nationale. Mais la cause qu'il plaide avec tant d'éloquence en faveur de la conversation est implacablement monologique. C'est la première et la plus énorme ironie, parmi toutes celles qui circulent dans ce texte, ironies qui s'interrogent et se complémentent, qui demandent notre attention, qui nous amusent et nous exaspèrent, qui nous tiennent sur un pied d'alerte.

Différentes cultures se heurtent dans Les Belles Âmes (2000), qui prend comme sujet un reality tour dans lequel des touristes bourgeois bien-pensants visitent certains des bas quartiers les plus sinistrés d'Europe, afin de mieux apprécier comment vivent les pauvres. On pourrait s'attendre à ce qu'ils soient dévastés par la misère qu'ils découvrent, ou tout au moins un peu inquiétés. Mais leur vision du monde demeure relativement intacte et inchangée, et c'est leur bienveillance même qui sert à les protéger d'une vraie appréciation des réalités sociales, lorsque ces réalités sont trop affligeantes. Pendant leur voyage, de Paris à Bruxelles, à 
Cologne, à Berlin, à Dresde, à Milan et Turin, ces réalités deviennent de plus en plus rudes, car les organisateurs du tour ont délibérément programmé les choses ainsi, souhaitant que les touristes rencontrent des exemples de catastrophe sociale de plus en plus dramatiques. Pourtant, les mécanismes de défense psychologique des touristes se déclarent à la hauteur des circonstances, et les remparts qu'ils ont construits autour de leur conscience morale et politique sont aussi lisses et raffinés que l'est cet étonnant roman lui-même.

Le Vif du vivant (2001), dont j'emprunte le titre ici, est un billet d'amour de Lydie Salvayre à Pablo Picasso. Dans un long essai sur les carnets de Picasso de 1964, Salvayre médite une multiplicité de choses : la notion de l'exil, par exemple, et les contraintes de vivre dans un pays qui n'est pas le sien ; la liberté et ses conditions de possibilité ; le rôle de l'artiste dans la société ; le principe de l'excès dans la créativité ; les modes différents de l'engagement politique. Picasso est une figure exemplaire pour Salvayre. Elle admire son énergie artistique, la franchise de son regard, l'originalité de sa vision. Plus que toute autre chose, elle est impressionnée par la manière dont son art plaide pour la vie telle qu'elle est, sans compromis, et par sa façon de nous obliger de regarder les choses de manière directe et sans réserve. De toute évidence, Salvayre aspire à un même esprit dans son propre travail, et dans ce sens Le Vif du vivant nous en dit long sur sa propre conception de l'art, et sur sa manière de se positionner en tant qu'artiste.

Écrit dans le style élégamment mordant qui est devenu sa signature, Contre (2002) est une condamnation intraitable de la société française contemporaine, centrée sur l'idée de la complaisance culturelle, politique et idéologique. Salvayre parle dans sa propre voix ici, ayant laissé tomber l'illusion 
que fournit la fiction. À l'origine une commande de France Culture pour les rencontres de La Chartreuse du Festival d'Avignon, spectacle pour poète et deux guitares, la première a eu lieu au mois de juillet 2001. La version imprimée du texte est complétée par un CD audio de la performance, avec Salvayre qui lit son texte, accompagnée des guitaristes Serge Teyssot-Gay et Marc Sens. Peu des contradictions de la société française échappent au regard de Salvayre ici. Elle parcourt les registres personnels et politiques, individuels et collectifs. Elle dénonce la façon dont les médias exploitent l'imagination sanguinaire du public, créant ainsi un climat de la peur. Elle souligne comment les défavorisés et les figures marginales de toutes sortes, surtout les pauvres, se trouvent diabolisés. Elle déplore la commercialisation de la culture contemporaine, suggérant que la seule musique valorisée par cette culture est celle des cours boursiers. Elle tourne en dérision la manière où ses concitoyens se dopent de romans sentimentaux et de croissants au beurre, quand ils ne sont pas en train de se gaver de drogues psychotropiques, sous les meilleurs conseils médicaux. Elle se plaint d'une société où les amants se retrouvent par email seulement, et où la sexualité doit être avant tout sans risque. Afin de résister à de telles tendances, elle estime que nous devons agir, et que notre action doit être fondamentalement oppositionnelle, un geste incendiaire qui commence par le mot « Non!».

Et que les vers mangent le bœuf mort (2002) réunit sept textes relativement courts d'inspiration diverse. Il y a des méditations sur des dynamiques familiales ; il y a une pièce où des couples dansant un tango se disputent ; il y a même un essai lapidaire et convaincant en faveur de la paresse. Des versions de Quelques Conseils utiles aux élèves huissiers et Le Vif du vivant figurent ici également. Dans une note accompagnant ces textes, Salvayre nous invite à les imaginer comme 
des êtres habitant les marges de ses romans, et de considérer leur caractère « indiscipliné, déviant, disparate » comme une vertu plutôt qu'un défaut.

Passage à l'ennemie (2003) raconte l'histoire d'Adrien Arjona, policier chargé d'infiltrer un groupe de jeunes délinquants dans une cité de la banlieue parisienne. Les rapports qu'il envoie à ses supérieurs, formulés dans une prose riche et richement amusante, font la chronique d'une quête qui dérape de façon tout à fait plaisante. Obligé de fumer des quantités impressionnantes de haschisch afin de préserver sa clandestinité parmi les « déviants sociaux » qu'il doit surveiller, Arjona sera vite obligé de reconsidérer son propre système de valeurs. Il trouve les membres du groupe curieusement simpáticos, individuellement et collectivement. Et surtout la mystérieuse, silencieusement séductrice Dulcinée, une jeune femme encombrée d'un passé lourd. Leurs crimes sont au plus des peccadilles, le genre d'aventure que tout adolescent essaie, et Arjona se demande pourquoi les autorités ont désigné ces jeunes gens comme étant particulièrement dangereux. Contre son gré, il en vient à soupçonner qu'une telle désignation est infondée, et même pernicieuse. Peut-être que le pouvoir doit créer des ennemis là où il n'y en a pas, afin de s'affirmer et de projeter le spectacle de son hégémonie. Cette considération, ainsi que d'autres tout aussi subversives, conduira éventuellement Arjona à commettre une sorte d'autodafé idéologique. Pire encore, écrivant rapport après rapport, Arjona en vient à réaliser qu'il adore écrire. Et peut-être, après avoir mené sa mission au bout, écrira-t-il un roman la racontant. Dans le monde que Lydie Salvayre nous propose ici, une telle issue n'est pas impossible, car c'est un monde qui favorise la métamorphose et la transformation, un lieu où par la force de leur volonté, les cochons se font pousser des ailes et prennent leur envol. 
Le narrateur de La Méthode Mila (2005) est un célibataire d'une quarantaine d'années qui s'appelle Fausto Arjona. C'est un homme solitaire et misanthrope qui s'est retiré de la compagnie de ses semblables et qui passe ses journées, agréablement, à lire la philosophie et à regarder des films pornographiques. Cette idylle prend fin pourtant lorsque sa mère, veuve, vient aménager chez lui. S'occupant d'elle, Arjona voit la mort inscrite un peu partout sur son corps vieillissant, ce qui lui fait horreur. Progressivement, il en vient à abominer sa mère, découvrant dans cette abomination un côté monstrueux de lui-même qu'il n'avait jamais soupçonné. Il cherche consolation dans le Discours de la méthode de Descartes, n'en trouvant point. Arjona ressent le besoin d'une tout autre méthode, et il en trouvera une dans les démarches de Madame Mila, clairvoyante qui lui parle de sa putative ascendance en Andalousie au douzième siècle, le nourrissant d'un ragoût généalogique pimenté de Musulmans, de Chrétiens et de Juifs. Elle lui fournit ainsi une histoire-et encore plus important, un récit finement adapté à ses besoins. La Méthode Mila met en scène une lutte ironique entre philosophie et fiction, et la façon dont Lydie Salvayre choisit de résoudre ce conflit en dit long sur sa foi en le roman comme forme culturelle.

Dis pas ça (2006) nous offre une expérience dans la veine de Contre, et la version imprimée ressemble de près à celui-ci, dans la mesure où le texte s'accompagne encore une fois d'un enregistrement CD où Salvayre lit son texte, accompagnée encore de Serge Teyssot-Gay et Marc Sens, cette fois avec le bassiste Jean-Paul Roy. Encore comme Contre, la pièce a été présentée au Festival d'Avignon. Mais la similarité la plus frappante, c'est celle du ton : Dis pas ça est un exercice de négation radicale. Dans une série de dix vignettes très brèves, Salvayre dénonce une multiplicité de scandales, 
concernant des secrets familiaux jalousement gardés, la manière dont les médias exploitent l'image de la femme, ou la façon dont la droite politique encourage le racisme. Sa voix est intransigeante, son regard indéfectible, et la manière dont elle met en lumière les gestes qu'elle estime scandaleux ne laisse aucune marge de négociation possible.

Dans Portrait de l'écrivain en animal domestique (2007), Salvayre nous donne un animal qui sait faire plaisir à son maître, faisant des cabrioles et prenant des postures soumises afin de gagner la faveur de ce dernier. Cette bête, c'est la narratrice elle-même, qui conclut un pacte faustien avec Jim Tobold, le soi-disant « roi du hamburger » dont l'empire fast-food a consommé le monde entier, tout comme le monde entier consomme ses hamburgers. Son job, c'est d'écrire sa vie : pas une simple biographie, mais plutôt un testament, un Évangile de Tobold où le principe du capitalisme sauvage sera enfin élevé jusqu'au rang divin qu'il mérite, grâce aux efforts de son seul vrai prophète. Plus qu'un scribe, la narratrice fonctionne comme un miroir dans lequel Tobold admire sa propre personne. Elle s'assied à ses pieds dans un état d'extase alors qu'il explique qui il a été, qui il est et qui il sera. Tobold respire l'air raréfié d'un individu dont la fortune se moque de la notion de la richesse. Citoyen du monde à l'heure qu'il est, bien loin de ses origines modestes en France, il est constamment en mouvement, voltigeant de continent en continent, prenant un de ses nombreux Gulfstream comme un être inférieur prendrait un taxi. Malgré elle, la narratrice trouve qu'un tel mode de vie-aussi cruellement philistin que cela aurait pu lui sembler avant l'abandon de ses principes - n'est pas sans récompenses. Elle côtoie des vedettes de première : George Clooney, $\mathrm{Me}$ lanie Griffith, Brad Pitt (sans Angelina), Leonardo DiCaprio, Sophie Marceau, Bill Clinton, et un Bill Gates étonnamment 
priapique. En termes de charme, elle estime que « Bob » De Niro est sans égal. Comme les autres textes de Salvayre, ce livre est intelligent et acerbe, à la fois amusant et inquiétant. Salvayre déploie la satire de façon multiple, mais surtout pour nous faire réfléchir sur l'art et le pouvoir, et plus précisément encore sur la manière qu'a celui-ci de l'emporter sur celui-là, le pouvoir persuadant l'art de se mettre sur le dos, afin de se faire caresser le ventre.

La satire est encore une fois l'outil de choix de Salvayre dans Petit Traité de l'éducation lubrique (2008). C'est un livre qui fête la sexualité humaine, animé par le désir et l'humour. Proposé comme un manuel destiné aux illettrés sexuels, le livre passe en revue une multiplicité de pratiques, avec un tact admirable. Son langage est extrêmement classique, châtié, un langage qu'on aurait pu croire inadapté pour certains actes parmi les plus vigoureux que Salvayre décrit. Mais c'est bien cela l'intérêt, car les tensions qu'elle construit contribuent de manière importante aux effets qu'elle cherche à produire. S'efforçant d'édifier les plus désespérément naïfs entre nous, Salvayre vise en fait les puritains, les gourous, les mollahs, les flics sexuels, et les gens rangés et crispés de toutes sortes, visant un vaste horizon avec le lanceflammes de son regard satirique. C'est un petit livre bien rafraîchissant.

Dans BW (2009) le talent de portraitiste de Salvayre se fait encore sentir, mais cette fois-ci elle peint d'après nature. Son sujet, c'est Bernard Wallet, son compagnon de longue date. Wallet (dont vous lirez le « Lydie Salvayre, écrivain baroque'n'roll » dans le volume présent) est un homme hors du commun, une figure rocambolesque qui aurait pu être un héros de roman, s'il n'avait pas été si absolument réel. Athlète au niveau olympique dans sa jeunesse, voyageur invétéré, observateur lucide de tendances idéologiques, fervent 
défenseur de la culture, Wallet a passé la majorité de sa vie dans le monde de l'édition. Il fonde les Éditions Verticales en 1997, où il publie des écrivains comme Yves Pagès, Gabrielle Wittkop, Olivia Rosenthal, Pierre Senges, Nicole Caligaris, Régis Jauffret, Maylis de Kerangal et Salvayre elle-même. Il quitte Verticales en 2008, et la même année il perd sa vision pendant un temps. C'est cette calamité qui inspire $B W$, où Salvayre inscrit ce que Wallet a besoin de dire à propos de sa vie, motivé par l'idée d'une cécité permanente. Aveugle, Wallet s'efforce de voir les choses en face, une posture que Salvayre partage sans compromis.

Dans les premières pages d'Hymne (2011) Salvayre remarque qu'elle ressent le passage du temps, et qu'elle a par conséquent envie d'écrire désormais seulement sur les choses qui la touchent le plus profondément, sur les œuvres qu'elle admire infiniment. Ici, l'œuvre en question, c'est le « Star-Spangled Banner » que Jimi Hendrix a joué à Woodstock, le 18 août 1969. Pour Salvayre, cette performance constitue un événement exceptionnel, quelque chose qui a marqué son moment, mais qui sert aussi à poser les termes d'une vision neuve. Sa perspective est parfois très personnelle, parfois historique, politique, sociale ou culturelle ; mais quel que soit le caractère de son regard, son analyse est toujours pénétrante. Elle voit beaucoup de choses différentes dans l'hymne national réinventé. L'articulation d'un « cri insoutenable » plus puissant que les mots ; un geste qui demeure totalement radical, même après quatre décennies; un «sanglot terrible » qui déchire l'espace qu'il libère. C'est à la fois courageux et intransigeant. Cela nie de façon directe la notion d'une Amérique unie et indivisée, la décrivant plutôt comme une pluralité, et proposant l'idée même de la pluralité comme force créatrice. Selon Salvayre, il s'agit d'une chose aussi belle que le dernier 
mouvement de la neuvième symphonie de Beethoven, aussi puissante que Guernica de Picasso. C'est une chose catégoriquement particulière et inimitable. La performance de Hendrix, dans son éloquence pure, nourrit l'imagination de Salvayre et l'encourage, à son tour, à mettre son propre talent d'artiste en œuvre.

Dans 7 Femmes (2013) Salvayre désigne sept écrivaines qui comptent beaucoup pour elle : Emily Brontë, Djuna Barnes, Sylvia Plath, Colette, Marina Tsvetaeva, Virginia Woolf et Ingeborg Bachmann. Pour chacune d'elles, la notion d'une vie simple ne suffisait pas, selon Salvayre. Elles ont toutes refusé l'ordre établi des choses, chacune choisissant d'inscrire ce refus dans leur écriture. Certaines ont hurlé et fait claquer les portes en écrivant ; d'autres ont écrit avec plus de grâce étudiée. Mais chacune en est venue à parler d'une voix tout à fait particulière et reconnaissable. Encore plus remarquable aux yeux de Salvayre est le fait que dans chaque cas l'œuvre s'est confondu avec la vie, sans égard pour les sacrifices nécessaires. Salvayre voit de la folie dans une telle décision, mais la passion qui la sous-tend l'intéresse bien davantage. Elle remarque qu'elle a relu les livres de ces femmes - tous les livres de ces femmes - pendant une période où elle trouvait l'écriture impossible. De toute évidence il y avait quelque chose dans cette expérience qui a servi à attiser sa propre créativité, résultant dans ce livre ainsi que d'autres à sa suite.

Le Prix Goncourt décerné à Lydie Salvayre pour Pas pleurer (2014) lui a valu un lectorat élargi, ainsi qu'une attention médiatique très considérable. Dans ce roman, Salvayre se penche sur certains de ses thèmes les plus chers : la dynamique de la libération personnelle, par exemple, et surtout la libération de la femme ; une fascination pour l'histoire et pour la manière dont le passé conditionne notre expérience 
du présent ; la volonté d'examiner les gestes spécifiques de la révolte ; le désir de donner voix à des gens qui, approchant la fin de la vie, se demandent ce qui leur est arrivé en chemin. Montse, la mère de la narratrice, se trouve au centre du récit. À l'âge de quinze ans, en pleine Guerre Civile, elle avait quitté sa maison natale afin de rejoindre les forces républicaines à Barcelone. Ce qu'elle a vécu l'a transformée, à deux niveaux différents. D'une part (et dans une perspective sociale et politique), elle a été fortement impressionnée par la ville révolutionnaire, et surtout par la ferveur révolutionnaire spécifiquement anarchique si largement répandue à Barcelone à l'époque. D'autre part (dans un registre plus personnel et intimiste), elle a été galvanisée par l'expérience sexuelle qu'elle y a connue, dont l'effet était aussi immédiat que profond. Dans le « maintenant » narratif du récit, Montse a quelques quatre-vingt-dix ans, et sa mémoire faiblit. Ses expériences de jeunesse lui semblent plus proches que tout ce qui lui est arrivé depuis, et elle parle à sa fille comme si le reste de sa vie ne comptait pas pour grandchose. Elle a abandonné tout ce qui lui paraît inessentiel ou supplémentaire afin de se concentrer sur les événements de sa vie qui lui semblent fondamentaux. Salvayre attire notre attention sur ce processus de vannage, suggérant que si cela vaut pour la vie, cela vaut également pour l'art.

Tout homme est une nuit (2017) aborde le thème de l'étranger, racontant l'histoire d'un homme qui arrive dans un petit village, inconnu et imprévu, pour s'y établir. Il souffre d'un cancer, et il cherche un endroit où se reposer. Au lieu de cela, c'est la malveillance qui l'attend, et la suspicion, et même la haine. Les villageois imaginent le pire à son sujet : c'est sans doute un monstre sexuel, ou un trafiquant de drogues dures, ou alors un Musulman. C'est la dynamique du groupe qui intéresse Salvayre, la manière dont 
le groupe se définit par opposition aux étrangers (sans qui le groupe n'aurait ni logique ni raison d'être). Le processus de diabolisation qu'elle décrit est terrifiant - et pourtant certains de ses lecteurs et lectrices reconnaîtront cela comme faisant partie du réel vécu. Cependant, de même que le groupe interroge l'étranger, l'étranger met le groupe en procès. Ces gestes ne sont pas parfaitement équilibrés certes, parce que les uns détiennent plus de pouvoir et d'influence que les autres. Tout de même, la subversion et la force de la résistance se rangent du côté de l'étranger, et ce sont deux principes qui fascinent Salvayre, depuis toujours.

Marcher jusqu'au soir (2019), son livre le plus récent au moment où j'écris ceci (et dont elle offre quelques extraits dans ce volume), résulte d'une invitation de passer toute une nuit, seule, au Musée Picasso, à Paris. S'il est largement question de Picasso encore une fois, il s'agit aussi d'Alberto Giacometti, car la visite de Salvayre a eu lieu pendant l'exposition Picasso-Giacometti organisé par le musée. Salvayre marche dans les couloirs du musée, contemplant L'Homme qui marche de Giacometti, cette construction si saisissante de notre frêle humanité. À quoi est-ce que cela sert, l'œuvre d'art, même (et peut-être surtout) lorsqu'il s'agit d'un geste aussi immense que celui de Giacometti. Qu'est-ce que nous devons faire de cela, pour qui est-ce, comment est-ce que nous pouvons le comprendre, quel sens est-ce que cela articule par rapport à notre vie, et d'ailleurs quelle vie est la nôtre, justement ? Voilà les questions que Salvayre se pose, et pas pour la première fois, car d'une manière ou d'autre ce sont des questions qu'elle invoque sans cesse depuis le début de sa carrière.

Prenant un pas en arrière et considérant cette carrière avec un peu de distance, un lecteur pourrait conclure que Lydie Salvayre a choisi de travailler là où l'expérience humaine 
rentre dans le vif du vivant. Dans ces moments où notre juste colère éclate, ou notre désir, notre deuil, notre indignation, notre peur, notre aspiration, notre pitié, notre espoir. Salvayre écrit dans l'urgence, soulignant des choses que nous avons ignorées mais qui nous concernent directement, soit individuellement, soit collectivement. Au début de cet essai j'ai suggéré que ses livres se jouent contre le grain de la société contemporaine, que nous pouvons les imaginer comme des antidotes contre les bêlements de ceux qui cherchent à nous contrôler et les flagorneries transparentes de ceux qui cherchent à nous séduire. Je suis persuadé que les livres de Salvayre peuvent nous aider à reconnaître certaines forces pernicieuses qui nous confrontent, et à y résister. Pourtant, ces livres nous offrent bien plus que cela, et je n'ai peut-être pas assez insisté sur la remarquable joie qui les anime, sur leur exubérance, sur la générosité d'esprit qu'on trouve dans chacun. Ce sont des effets hospitaliers qui servent à nous accueillir dans les mondes que ces livres esquissent, qui suggèrent que nous y sommes bienvenus, qu'il y a justement une place pour nous dans ces mondes. 
Lydie Salvayre et Warren Motte

\section{Une conversation avec Lydie Salvayre}

WM : Tout d'abord, puisqu'il s'agit ici d'une conversation, j'aimerais vous demander ce que vous pensez du principe. Beaucoup de vos livres, surtout au début de votre carrière (je pense par exemple à La Déclaration, à La Vie commune, à La Puissance des mouches, à La Compagnie des spectres) sont monologiques. Dans La Conférence de Cintegabelle, livre strictement monologique, le conférencier prône les vertus de la conversation - et cependant il fait tout pour tuer dans l'œuf toute possibilité de dialogue. Comment voyez-vous la chose?

LS : Aussi loin que remontent mes souvenirs, j'ai toujours eu des difficultés à prendre la parole. Comme vous le savez, mes parents qui étaient arrivés en France en 1939 pour fuir le franquisme parlaient une langue mixte et transpyrénéenne où le français était régulièrement piétiné, bousculé, estropié, bref mis à très rude épreuve. Le problème c'est que je reproduisais, enfant, leurs fantaisies et écarts langagiers, et que j'éprouvais une honte affreuse chaque fois que j'étais prise en défaut de mal dire. Ce n'est que plus tard, bien plus tard, que j'ai trouvé à ce mal dire transmis par mes parents, une puissance poétique,

Published in Lydie Salvayre, maintenant même, ed. Warren Motte (Lincoln, NE : Zea Books, 2021). doi: 10.32873/unl.dc.zea.1282 
une drôlerie, une forme d'impertinence et une façon joyeuse de résister à la langue majoritaire dont j'ai tenté de rendre compte dans mon roman Pas pleurer.

Mais à l'école j'appréhendais toujours de mal dire en reproduisant à mon insu le fragnol familial. Et cette crainte de mal dire me conduisait fatalement à mal dire, j'en ai gardé quelques souvenirs cuisants. Chaque fois que j'étais mise en demeure de répondre à mon institutrice, je trébuchais sur les mots comme sur des pavés et ne parvenais pas à trouver d'autre passage entre ma tête et ma bouche qu'un chemin plein de ronces où je me prenais la langue (comme on dit se prendre les pieds dans le tapis).

De plus, j'avais compris très vite, et bien avant de lire Bourdieu, que les façons de parler étaient un signe impitoyable de distinction sociale. Je ne sais si l'on constate la même chose aux USA, mais en France, la parole révèle immédiatement l'origine et l'appartenance de celui qui la profère. Or parler pour moi, dans l'enfance, revenait à avouer ce que je concevais alors comme une double tare : être la fille à la fois d'étrangers et de prolétaires.

De plus j'avais (et j'ai toujours je crois) le sentiment que les mots n'étaient qu'un pâle reflet de mon ressenti ou, pire, la trahison de ce ressenti.

Mais si je souffrais d'un empêchement profond à parler, j'étais en revanche affamée de lectures, une chose compensant l'autre probablement; et c'est cet appétit littéraire démesuré, cet amour immodéré de la « belle langue » qui, je crois, m'a sauvé la mise, le mot n'est pas trop fort. Car oui je m'exprimais incorrectement à l'oral, oui je cherchais péniblement mes mots, oui je parlais comme une vache espagnole 
(c'était la formule en vigueur), mais je connaissais des formules, des tournures grammaticales, des mots savants dont les autres ignoraient l'existence (encore aujourd'hui la découverte d'un mot rare me plonge dans le ravissement) et des fictions qui me faisaient rêver.

Il m'arrive d'ailleurs de penser que c'est grâce à cet empêchement à parler que je suis devenue écrivain.

Cette incapacité, je l'ai gardée longtemps et je la garde encore, en dépit des efforts laborieux pour améliorer ma locution, en dépit des innombrables entretiens auxquels je me suis prêtée, en dépit de mes passages à la télévision, en dépit des conférences publiques ... À chaque fois, la vieille appréhension d'enfance de mal dire me saisit et j'éprouve toujours la même peine à la surmonter.

Vous comprenez pourquoi le titre qui s'imposa à moi lorsque j'écrivis mon premier roman fut $L a$ Déclaration. Tout ce que je n'arrivais pas à exprimer par la parole orale, tout ce qui restait prisonnier dans ma maison intérieure, tout ce que je ne savais que balbutier, tout ce qui demeurait improféré, inarticulé et lourd à mon cœur, trouvait enfin à se déclarer dans une parole écrite. Je pouvais même, par l'écriture, me payer le luxe ironique de donner la voix dans $L a$ Conférence de Cintegabelle à un double qui n'était rien de moins que : professeur de conversation !, et à un autre dans la Puissance des mouches qui officiait comme guide (fort prolixe) dans un musée. Revanche délicieuse.

Vous comprenez aussi pourquoi je fis le choix d'être pédopsychiatre, métier que j'exerçais jusqu'en 2012 et qui consistait essentiellement à amener les 
enfants à verbaliser une souffrance qu'ils ne savaient pas nommer.

WM : Tout le monde a ses tics, ses singularités, ses manies, ses excentricités, bref ses différences. Les individus se définissent par leurs différences. Nous savons cela, mais souvent nous faisons comme si nous ne le savions pas, par indifférence, par lassitude, par méchanceté parfois. Vos livres revendiquent activement le droit à la différence, et plus que tout autre auteur, vous insistez sur cette leçon fondamentale. S'agit-il d'un principe que vous mettez en action stratégiquement, ou s'agit-il plutôt d'une simple manière d'être chez vous?

LS : C'est une banalité, mais je crois qu'il est bon de la redire : il n'y a parole que s'il y a de l'autre, de l'altérité. Dans un monde de mêmes : pas de parole. On le constate dans ces groupes clos sur eux-mêmes et adhérant à la même idéologie : parole morte. Ou dans certaines familles, je pense à celle que décrit Fritz Zorn dans Mars dans laquelle la parole parce qu'empêchée, parce qu'interdite, devient littéralement cancérigène et tue.

Or souvent nous vivons dans un confortable et mortifère « entre-soi ». Les artistes vivent dans l'entre-soi, les bourgeois dans l'entre-soi, les classes moyennes dans l'entre-soi, les pauvres dans l'entresoi, les intellectuels dans l'entre-soi ... Et cet entresoi est tel, parfois, que tout surgissement d'une différence, même minime, y apparaît comme une menace (c'est un peu la mécanique à l'œuvre dans Tout homme est une nuit). 
Les écrivains et leurs écrits ne sont pas à l'abri de cet entre-soi étouffant. Aussi, pour me prémunir de ce que je considère comme une faillite, j'ai toujours à l'esprit cette remarque de Hanna Arendt dans Qu'estce que la politique. Elle y dit ceci : il y a ceux qui vivent dans ce qu'elle appelle le désert-monde : c'est-à-dire ceux qui n'ont pas accès à la culture, ceux qui vivent sans vivre, ceux qui subissent leur destin et dont la parole ne compte pour rien ; et il y a ceux qui vivent dans des oasis bénis, où la parole circule, où l'art, la littérature sont présents, où la poésie existe, où l'on se serre fraternellement la main ... Mais, avertitelle, si les habitants de l'oasis restent entre eux, délicieusement confinés, s'ils ne s'adressent qu'à des mêmes, qu'à des doubles d'eux-mêmes, s'ils ne vont pas se salir dans le désert-monde, alors non seulement le désert-monde restera le désert-monde, mais leur oasis à leur tour s'ensablera.

Je ne veux à aucun prix que la littérature s'ensable. Je ne veux à aucun prix que mes livres s'ensablent. Je veux au contraire qu'ils soient le lieu où les différences dont vous parlez soient accueillies. Et je veux, en premier lieu, que la langue héberge et incarne ces différences. D'où mon goût profond, je vous l'ai déjà dit, pour le brassage des registres : populaire et noble, grossier et sublime, comique et tragique, citations érudites et chansons de variétés, références aux textes classiques et aux magazines de mode, références aux grands auteurs classiques et aux auteurs baroquissimes, voix de celle que je crois être moi et voix de l'étrangère en moi...

Mais je n'ai sans doute aucun mérite à brasser ces différents registres, puisque je suis moi-même 
transfuge, transfuge c'est-à-dire quatre fois traître, traître à la classe populaire de laquelle je me suis arrachée mais à laquelle je reste charnellement liée, oui charnellement et pour toujours, traître à la classe bourgeoise dont je me suis appropriée la langue, qui m'a fait une place en son sein mais que je malmène avec délectation, traître à la langue espagnole qui est ma langue maternelle et qui travaille souterrainement le français, et traître à la langue française que j'adore malmener et mettre hors d'elle.

Je ne sais quel philosophe disait que chaque être est une foule. Je suis une foule. Vous êtes une foule. Le livre est une foule, une foule parfois constituée par un seul personnage, lui-même constitué d'une foule.

Pour répondre précisément à votre question c'est donc à la fois une stratégie et ma manière d'être, et peut-être plus que ma manière d'être, ma constitution même, ce qui me fonde.

Encore une remarque qui n'est pas sans relation avec ce dont nous parlons : si l'on se penche sur la langue française, mais je pense que cela est vrai pour les autres langues, on s'aperçoit qu'elle est tissée d'une infinité de mots migrants, je veux dire de mots venant de l'arabe, de l'espagnol, du russe, de l'anglais ... dont elle fait son miel. C'est sans doute que la langue est moins regardante (je ne sais quel qualificatif employer) sur l'origine des mots qui la constituent que les hommes qui la parlent.

WM : Quel est le rôle de l'ironie comme technique de résistance dans votre écriture? Que peut l'ironie contre le pouvoir assis ? Et d'ailleurs que peut la littérature à notre époque, où le pouvoir se moque tout à fait 
ouvertement de la poésie, du rêve, de l'imagination esthétique?

LS : Vous savez combien j'aime Blaise Pascal puisque j'ai fait du défenseur autodidacte de ses Pensées le personnage principal de la Puissance des mouches. Eh bien Pascal, l'austère Pascal, l'ascétique Pascal disait : philosopher c'est se moquer de la philosophie. Je crois qu'on pourrait dire la même chose de la littérature.

Je crois qu'on pourrait dire qu'écrire c'est se moquer d'écrire, ce qui suppose donc au préalable une capacité à se moquer de soi avant de se moquer des autres, c'est se départir de l'esprit de sérieux qui, lui, ne laisse aucune place au doute, à l'imprévisible, à l'ambiguïté, à la déroute, à la polysémie, c'est passer de l'extrême élégance du « bien-dire » à la pire des grossièretés, histoire d'affirmer que nous ne sommes pas faits d'une seule langue, mais d'une infinité, c'est conjuguer le verbe niquer à l'imparfait du subjonctif (dans La Méthode Mila), c'est aborder les questions graves de telle sorte qu'elles n'effarent pas car l'effarement paralyse la pensée, c'est croiser notamment le comique avec le tragique comme s'y emploie et souvent à son insu la mère de La Compagnie des spectres, laquelle fait pleurire comme disait, je crois, Queneau, c'est se moquer des pouvoirs qui tolèrent si mal qu'on puisse rire d'eux (l'on sait tous qu'une remarque rieuse sur un homme puissant peut s'avérer plus efficace que la plus sérieuse des analyses, l'une d'ailleurs n'excluant pas l'autre), c'est saper les postures d'autorité, c'est saper par exemple la posture d'autorité du conférencier de La Conférence de Cintegabelle en lui attribuant quelques ridicules touchants, c'est 
retrouver le plaisir de jouer de l'enfance, le plaisir enfantin (et sérieux) de jouer avec la langue, comme le fait, plus ou moins candidement, la mère de Pas pleurer : c'est le cadeau de mes soucis, c'est tombé à pic nommé, je me raccorde (pour je me rappelle) qui vient du verbe espagnol recordarse : se souvenir, etc.

C'est aussi le plaisir de faire rire le lecteur, de le faire rire d'un rire noir quelquefois, d'un rire énorme et gargantuesque d'autres fois, ou subtil, ou ironique et léger, ou innocent et pur de tout sarcasme. Car on ne dira jamais assez combien sont généreux les livres qui font rire, combien sont généreux pour le lecteur Cervantès, Rabelais, Quevedo, Molière, Shakespeare, Sterne, Beckett, Chevillard ...

Je rappelle à propos du rire, qu'il fut souvent dans l'histoire, et dans l'histoire religieuse en particulier un objet de scandale. Dans Le Nom de la rose de Umberto Eco, le bibliothécaire massacre les lecteurs du second volume de la Poétique d'Aristote pour la simple raison que celui-ci est consacré à la comédie, autrement dit au rire.

WM : J'ai l'impression que le scandale joue un rôle important dans beaucoup de vos livres, dans ce sens où tout part de là, que le scandale met tout en marche, et sert ensuite à nourrir ou à attiser le récit. Comment voyez-vous le scandale, comment imaginez-vous le côté contagieux du phénomène, le fait que cette réaction soit transmissible?

LS : À l'origine-je l'ai vérifié-scandale est un mot de l'écriture sainte qui désigne ce qui fait chuter, ce qui fait obstacle sur la voie droite, ce qui déroge aux 
règles en vigueur, ce qui met conséquemment du désordre...

Mais n'est-ce pas la définition même de la littérature? Pour peu que l'on considère qu'un livre est un coup de hache qui brise en nous la mer gelée (lettre de Kafka à Oskar Pollak, janvier 1904), la mer gelée de notre langue, la mer gelée de nos pensées et la mer gelée de nos émotions, un livre n'est-il pas forcément scandaleux?

Et si ce scandale est inhérent à la littérature, n'explique- $t$-il pas que Rabelais fut censuré par La Sorbonne, que Mandelstam mourut en exil, que Flaubert fut condamné pour Madame Bovary, Baudelaire pour ses Fleurs du mal, que Éden, Éden, Éden de Pierre Guyotat fut frappé d'interdiction en 1970, et je pourrais ainsi infiniment prolonger la liste.

En quoi consiste donc ce scandale qui serait propre à la littérature ?

Les œuvres des écrivains que je viens de mentionner ont ceci en commun qu'elles inventent une façon nouvelle de nommer les hommes et le monde, et par ce seul fait, de remettre en cause l'ordre sexuel, moral, religieux et politique.

Elles nous rappellent que cet « acte inconnu » qu'est une parole authentique, habitée, absolument singulière, peut par sa seule profération amener le scandale dans un monde où nous sommes parlé plus que nous ne parlons et où nous sommes pensés plus que nous ne pensons.

Pour le dire autrement, c'est, je crois, l'introduction de la vie dans la langue qui fut et reste un scandale, c'est la vie qui, parce qu'elle est mouvement, parce qu'elle est désir, parce qu'elle est surgissement 
de l'imprévisible, perturbe l'ordre et le sens des phrases.

Et s'il est vrai, comme l'écrit Deleuze, que c'est le passage de la vie dans le langage qui constitue les idées, raison de plus de se méfier de ces idiots de la littérature! Je pense à ces idiots magnifiques qui font scandale sans le savoir et le vouloir par le simple fait qu'ils accordent leur désir avec leur conduite, leur vie avec leur pensée, ces idiots que j'aime entre tous, je pense au Quichotte, à Bartleby, au Prince Mychkine, au Brave Soldat Chvéïk . . . dont la candeur et la bonté sont si grandes qu'elles en paraissent suspectes, dont l'insouci de la bienséance est tel qu'elle les fait passer pour fous ou pour inadaptés, dont l'exigence de vérité et de justice est telle qu'elle effare tous ceux qui s'accommodent confortablement du mensonge et de l'injustice, ces idiots qui tous parlent ouvertement parce qu'ils ne peuvent même pas imaginer la nécessité de la prudence.

La mère de la Compagnie des spectres se situe assurément dans cette lignée scandaleuse. Elle hurle contre Pétain, elle l'injurie, le traite de putain et fait littéralement scandale dans son village pour la seule raison qu'elle dit ingénument et à voix haute ce qu'il est interdit de dire et même de penser dans la France de 1940 occupée par les Nazis.

Augustin dans Tout homme est une nuit fait lui aussi scandale dans son village en opposant naïvement à la vision refermée et peureuse des clients du Café des Sports, une autre vision possible des rapports entre les hommes dont il s'étonne qu'elle ne soit pas partagée par tous.

Comme José dans Pas pleurer qui rompt, au nom 
de la vie et de ce qu'il pense être la liberté, avec des siècles de soumission paysanne aux grands propriétaires terriens.

Ces personnages ne font pas du scandale pour faire du scandale. Ils sont même très éloignés de toute idée de provocation. C'est simplement la radicalité et le vivant de leur désir qui fait d'eux des êtres de scandale. Ce qui me permet de restituer ici au terme de radicalité l'énergie créatrice et la beauté virulente que lui ont confisquées les nouveaux idiomes, lesquels l'associent au pire des extrémismes, au pire des fanatismes et à l'exercice de la pire terreur. Or la radicalité c'est tout le contraire. La radicalité c'est le courage des ruptures qui permettent à chacun de se réapproprier la parole et le désir perdus, d'ouvrir un chemin vers sa propre émancipation, d'exercer sur le monde sa puissance critique et d'accéder aux imaginations les plus inventives et les plus inespérées.

WM : Est-ce que vous arrivez à imaginer votre travail, vos livres, de manière globale, comme une « œuvre » ? Et si oui, qu'est-ce qui constituerait leur cohésion, le ciment qui permettrait à concevoir vos livres comme un tout? Est-ce que vous voyez un trajet quelconque dans la manière dont votre écriture a évolué depuis vos débuts?

LS : Je commence à peine à entrevoir quelques linéaments et peut-être leur raison d'être.

La chose aujourd'hui qui m'apparaît comme la plus évidente est la présence presque constante dans mes romans d'une figure paternelle autoritaire : Pétain dans la Compagnie des spectres, Molinier dans la 
Puissance des mouches, le père despotique de Josep et Montse dans Pas pleurer ... Et sans vouloir faire de la psychanalyse à deux balles, la raison de cette insistance me saute enfin aux yeux : je suis née, j'ai grandi auprès d'un père paranoïaque qui me terrifiait et qui me terrifia longtemps, jusqu'au jour où il fut interné à l'Hôpital Psychiatrique de Toulouse pour un délire persécutoire déclenché par l'agrandissement illégal de la maison voisine qui amputait une partie de son jardin de sa vue panoramique.

De ce jour, je fus délestée de ma peur comme si le terme médical apposé sur sa violence par le médecin l'avait désarmée (sa violence), l'avait délivrée de sa part obscure parce qu'innommée, comme si le diagnostic de psychose paranoïaque était venu attester scientifiquement l'immense vulnérabilité sur laquelle son délire avait germé, l'écheveau compliqué des déconvenues, des chagrins, des brimades, et des humiliations qu'il avait endurés en tant qu'ouvrier dans le bâtiment, de surcroît étranger, de surcroît communiste, de surcroît orphelin dès l'enfance, et la profondeur d'une douleur morale dont j'avais subi les effets destructeurs sans jamais comprendre (non, non, comprendre n'est pas excuser) sans jamais comprendre qu'ils étaient les symptômes d'une âme ravagée.

Jusqu'à son internement, j'avais cru que tous les pères dégrafaient leur ceinture pour attraper au lasso leurs enfants en visant leur cul ou leurs jambes.

J'avais cru que tous les pères envoyaient des gifles à leur femme lorsque le rôti était froid.

J'avais cru que tous les pères cachaient un fusil sous le lit, au cas où leur voisin deviendrait menaçant. 
J'avais cru que tous les pères interdisaient à leur fille d'aller à la fête du village parce qu'elle courait le risque de subir des tripotages.

J'avais cru que tous les enfants tremblaient devant leur père et qu'ils souhaitaient sa mort, j'avais cru que c'était normal, que ce scandale était normal, que ce scandale était de règle, que tous les enfants se pliaient à la démence acceptée d'un seul, et que c'était la loi.

Je compris que ça ne l'était pas le jour où on l'interna.

De cet évènement familial, je n'ai pu parler que tout récemment, dans le récit qui sortira dans quelques mois. Jusqu'alors, je l'avais tu, ou évoqué de façon très allusive. Ce qui me permet du reste de mesurer le temps incroyable qu'il faut à certains éléments d'une vie pour parvenir à une forme littéraire juste, juste je veux dire ni autocomplaisante, ni sentimentalo-larmoyante, ni qui suscite un quelconque apitoiement, bref qui soit à la bonne distance, au bon rythme, au bon souffle, et surgie au moment opportun.

Je me demande souvent quelles traces la présence de ce père paranoïaque a laissées en moi et en ce que j'écris. Ça m'est difficile à dire. Mais il y a en tous cas un bénéfice que j'ai acquis, grâce à lui en quelque sorte, et que je constate à chaque fois : c'est qu'il a développé en moi une sensibilité sauvage et presque maladive à la toxicité des pouvoirs autoritaires, de tous les pouvoirs autoritaires, jusqu'à ceux qui n'en ont pas la forme, jusqu'à ceux qui prennent des allures apparemment douces et prétendument démocratiques, jusqu'aux plus aimants. 
WM : Une dernière question, si vous le voulez bien. Selon vous, qui est votre lecteur, votre lectrice? Par là je veux dire deux choses différentes, je suppose. D'une part, lorsque vous êtes en plein travail, pour qui écrivez-vous? D'autre part (et avec un peu plus de recul), comment imaginez-vous les individus dans le monde réel qui vous lisent?

LS : $\quad$ Mon lecteur idéal, j'en ai fait, je crois, le portrait dans La Puissance des mouches : c'est le guide du musée de Port-Royal consacré en partie à Blaise Pascal.

Il est pour moi un lecteur idéal puisqu'il ne lit pas Les Pensées de Pascal pour briller dans un dîner mondain, ni pour écrire une savante exégèse, ni pour obéir à je ne sais quel engouement du moment, ni pour vérifier je ne sais quelle interprétation, ni parce qu'il y est d'une certaine façon contraint, ni pour mieux trouver le sommeil ou l'évasion, ni pour faire étalage de sa culture...

Il lit passionnément Les Pensées pour le sens qu'il croit y trouver et il les lit pour le plaisir. Il les lit et les lisant, il les fait siennes, il les réinvente, il les repense à sa façon, et surtout il les met en ouvre dans sa vie même. C'est un lecteur créateur.

Car le livre n'est pas pour lui une chose pasteurisée, stérilisée, abstraite, qu'on range une fois lu dans une bibliothèque.

Le livre n'est pas pour lui du papier, c'est du feu.

Le livre n'est pas pour lui lettre morte, mais lettre vive, dynamique, machine à créer, à penser.

Le livre lui parle personnellement. Et il n'est en rien séparé de sa vie. Il imprègne sa vie. Il la féconde. $\mathrm{Au}$ point qu'il l'agit et la transforme. Au point qu'il 
produit en lui une révolution intérieure, ce sont les mots que Nietzsche utilise après sa lecture passionnée de Schopenhauer.

Son régime de lecture n'est pas celui de l'ingestion passive mais celui du désir, du vertige.

D'ailleurs il lit couché (comme moi). Sans doute parce que la position couchée est tout à fait l'inverse de la position qu'on exige à l'école. Et c'est logique, puisque lire c'est désobéir.

C'est désobéir aux injonctions qui nous viennent du dehors et font fi de nos désirs.

C'est désobéir à l'impératif d'être actif et de rentabiliser le temps puisque la lecture, on le sait, c'est du temps perdu.

C'est désobéir à la tentation d'être happé par le flot d'images qui nous submergent.

C'est désobéir aux injonctions de prudence, puisque lire est un exercice risqué (puisqu'il amène à penser).

C'est désobéir aux préjugés et aux mots d'ordre idéologiques puisque la littérature, en ce qu'elle a de meilleur, leur livre des batailles.

C'est désobéir à l'impératif de transparence car les livres, disait Levinas, sont les gardiens de notre vie intérieure.

Et puisque j'en viens à citer Levinas, je voudrais rappeler cette pensée de lui qui me paraît plus importante que jamais par ces temps difficiles. Il dit que ce qui fait de l'homme un humain ce n'est pas son appartenance au terroir, ni son appartenance à la religion, ni son appartenance à une quelconque communauté ou à un quelconque parti, c'est son appartenance aux textes. Cette appartenance aux textes 
lui assure qu'aucune racine ne le retient captif d'un sol, qu'aucune voix du sang ne l'oppresse, qu'aucun dogme ne l'emprisonne et que son esprit reste souverainement libre.

La condition absolue d'une lecture heureuse, me semble-t-il, est qu'elle soit un exercice de liberté.

J'ai eu cette chance au fond, dans l'enfance, de n'avoir pas eu près de moi quelqu'un susceptible de me dicter ce qu'il y avait à comprendre ou ne pas comprendre dans Sans famille (premier roman lu à dix ans dans une exaltation extraordinaire). Car s'il est, me semble-t-il, une chose préjudiciable à la lecture, c'est cette tradition pédagogique qui se fonde sur l'idée qu'un livre serait dépositaire d'une intention précise ou d'un sens déposé par l'auteur qu'il s'agirait de déchiffrer, qu'il y aurait une vérité qui serait la juste, la vraie, l'officielle, la légale qu'il faudrait déterrer à toute force.

Or je crois qu'il y a dans un livre une infinité de lectures possibles et une infinité de sens possibles, d'abord parce que le texte excède toujours les intentions de son auteur, mais surtout parce que chaque lecteur associe à sa lecture ses propres questions, sa propre culture, ses propres fantasmes, ses propres obsessions, et son propre inconscient. Dans ma lecture exultante de Sans famille ce qui m'importait alors et qu'aucun professeur au monde même le plus génial n'aurait pu me souffler, c'était une interrogation totalement personnelle et qui concernait une problématique familiale.

Pour finir notre entretien sur une note heureuse, je voudrais faire une citation de Gombrowicz qui insistait, car je ne l'ai pas assez fait, sur la dimension 


\section{UNE CONVERSATION}

de plaisir inhérente à la littérature et à sa lecture. Il disait ceci : Si la littérature ose en général parler, ce n'est nullement parce qu'elle est sûre de sa vérité, mais parce qu'elle est sûre de sa volupté. Je le confirme. Lire et écrire sont les plus grandes voluptés que je connaisse. 


\section{Lydie Salvayre}

\section{Deux artistes}

\section{1) Sur Alberto Giacometti : Walking}

Je nourrissais depuis longtemps une passion pour l'Homme qui marche de Giacometti. L'Homme qui marche, que je n'avais jamais vu que reproduit sur du papier glacé, me semblait constituer l'œuvre au monde qui disait le plus justement et de la façon la plus poignante ce qu'il en était de notre condition humaine: notre infinie solitude et notre infinie vulnérabilité, mais, en dépit de celles-ci, notre entêtement à persévérer dans le vivre, notre entêtement à persévérer contre toute raison dans le vivre.

L'Homme qui marche, immobile, figé, et en en même temps mouvant, comme ces vagues de la mer que le froid a gelées dans leur houle.

Solitaire, absolument solitaire, absolument impénétrable, clos, retranché en lui-même, hors d'atteinte.

Dur, d'une dureté infracassable, immortel, inhumain.

Et frêle, frêle, éprouvé, calciné disait Genet comme au sortir d'un four, brûlant et pétrifié,

penché vers l'avant sous le poids d'un fardeau invisible qui courbe ses épaules, sachant que Dieu est mort et qu'il n'y

Published in Lydie Salvayre, maintenant même, ed. Warren Motte (Lincoln, NE : Zea Books, 2021). doi: 10.32873/unl.dc.zea.1283 
a pas d'arrière-monde, pas de consolation, pas de promesse, pas de secours, pas d'issue devant la terreur du néant.

Dépouillé de tout superflu, de toute affectation, de tout fard et de toute arrogance.

Sans truquage.

Fait de presque rien.

D'une singularité absolue dans un monde de mêmes.

$\mathrm{Nu}$. Dans un pur dénuement, je veux dire dépouillé de toutes ces babioles sensées nous consoler du vide et de l'angoisse qu'il engendre.

Décharné, la peau sur les os, décharné dans un monde obèse, dans un monde de la production obèse, dans un monde de la consommation obèse.

Décharné mais lourd, lourd peut-être de son savoir sur la Shoah et les martyrs de Buchenwald.

Vieux. Éprouvé. Revenu harassé des batailles pour vivre, et des coups encaissés.

Courbé par le poids du monde et peut-être par la honte de l'avoir fait tel,

D'une infinie vulnérabilité. Aussi fragile qu'une herbe, qu'une brindille. Aussi désarmé. Aussi rien.

Pauvre parmi les pauvres. Jetable. Un migrant. Un mort aux autres. Puisque je le voyais avec les yeux de mon époque chargés d'images de misère et d'hommes errants et sans patrie. Ou frère jumeau de ma mère qui déterrait les betteraves dans les champs parce qu'elle n'avait rien d'autre à manger durant ce qu'on appela pudiquement la retirada.

Doté d'un corps noueux, malingre et comme rongé par l'acide du monde. Un corps disharmonieux. Contrefait. Piedbot. Infirme presque. Tout l'inverse du corps lisse, poli, laqué, décoré, fessu, rebondi, maquillé, bodybuildé, bref chosifié et comme fabriqué sur mesure que nous vendaient les pubs et les sœurs Kardashian. 
Au bord de l'extinction. Et peut-être aux portes de la mort.

Et cependant marchant, marchant, marchant, marchant, marchant, continuant de marcher, continuant bravement de marcher et de regarder droit devant, continuant de marcher d'un grand pas, sans flancher, continuant de marcher dans un univers de décombres, malgré le non-sens, malgré le peu d'espoir, malgré l'absurdité, malgré l'absolue solitude, malgré la violence des hommes, malgré la précarité des choses et malgré toutes les apocalypses annoncées, continuant de marcher parce que cesser de marcher signifie mourir, continuant de marcher contre le vent et les défaites, tout comme Giacometti, tout comme moi, tout comme nous.

\section{2) Sur Thomas Bernhard : Contre}

Aller dans le sens opposé, c'est ce que ne cesse de se répéter le narrateur de La Cave.

Aller dans le sens opposé au chemin qui le conduit au lycée bourgeois, fréquenté par des enfants bourgeois, situé dans un quartier bourgeois avec ses maisons bourgeoises, ses commerces bourgeois et ses jardins bourgeois.

Aller dans le sens opposé au chemin que lui imposent ses professeurs, loin très loin de l'école où il n'a rien appris d'utile et où ses qualités ont été étouffées par des méthodes d'éducation héritées du national-socialisme et qu'il juge répugnantes.

Aller dans le sens opposé au chemin que lui impose plus ou moins insidieusement sa famille.

Aller dans le sens opposé au chemin que lui impose plus ou moins insidieusement son grand-père adoré qui le voudrait artiste. 
Aller dans le sens opposé au chemin que lui impose plus ou moins insidieusement l'idéologie dominante.

Aller dans le sens opposé au chemin que lui impose plus ou moins insidieusement la société toute entière

Aller donc à l'opposé de tout, puisque tout dans cette société contribue à la bêtise, à l'abaissement, à la dégradation et à la méchanceté des hommes.

Aller à l'opposé de toutes les assignations quelles qu'elles soient, à l'opposé de toutes les inscriptions sociales quelles qu'elles soient, de tous les ancrages, de tous les attachements.

Toute l'intelligence de Thomas Bernhard qui prête sa voix au narrateur de La Cave, autre lui-même, toute sa sensibilité, toute sa force, tout son courage sont tendus vers cette exigence d'aller contre tout ce qui, plus ou moins consciemment, guide les pas des hommes et leur semble aller de soi,

contre l'histoire nationale autrichienne qu'il exècre, avec son passé infâme, ses secrets honteux, tous ses mensonges et son hypocrisie (Maîtres anciens),

contre l'optimisme abject des nantis, lequel ne repose que sur le mépris, l'ignorance ou l'indifférence devant la misère des autres comme les manifestent les bourgeois de Salzbourg à l'égard de la cité Scherzhauserfeld, la cité des pauvres de La Cave, qui n'est à leurs yeux qu'une tache de boue, une marque infâme, le lieu de la racaille, la pourvoyeuse des tribunaux, l'antichambre de l'enfer,

contre la maladie (la tuberculose pulmonaire) et contre la médecine, pour guérir par ses propres moyens ainsi que le décide le narrateur du roman Le Froid, et faire de ce malheur une chance pour l'œuvre,

contre les convenances, contre la politesse qui nous oblige à la mesure ou à l'euphémisation, contre ce qu'on appelle les précautions d'usage, contre les prudentes périphrases qui n'osent pas mordre ni dénoncer, et pratiquer 
résolument l'invective, l'ironie, la satire rageuse, l'imprécation véhémente, la fureur la plus noire et la plus outrancière s'il le faut, et tant mieux si elle offusque les âmes délicates,

contre l'indolence, contre la torpeur, contre le renoncement, contre le désespoir et le désir de mort qu'instillent certains lieux et notamment Salzbourg (L'Origine).

contre les lectures des écrivains auxquelles l'a obligé l'école autrichienne, pour lire avec passion les français Montaigne, Diderot, Voltaire, Pascal le plus grand, les russes Gogol, Dostoïevski, et d'autres,

contre le sérieux culturel et contre l'arrogance, la prétention, l'exhibition et le ridicule des gens dits cultivés ( les époux Auesberger dans Des arbres à abattre), pour en rire d'un rire énorme

contre enfin et peut-être surtout, contre la langue habituelle, contre la langue normée, contre la langue moyenne, pour écrire dans la langue la plus musicale qui soit.

Ce contre-mouvement, cet aller à l'opposé du sens obligatoire, ce demi-tour à cent pour cent, le narrateur de La Cave, a la conviction qu'il doit le faire impérativement, c'est maintenant ou jamais se dit-il. Et avec le recul, il acquiert la certitude que sa décision, à ce moment-là de sa vie, fut la bonne.

Et ce demi-tour qu'il opère dans un geste de survie est un demi-tour radical. Radical, un mot qu'il faudrait aujourd'hui sauver, un mot auquel on devrait restituer la force et la beauté violente que lui ont confisquées les nouveaux langages en l'associant au pire des extrémismes, au pire des fanatismes et à la pire des terreurs. Si bien que radical est devenu aujourd'hui un mot d'opprobre. Si bien qu'il ne désigne plus que ce qui doit être à tout prix évité, chassé, dézingué. Ou pire rééduqué.

Le narrateur de La Cave opère un demi-tour radical puisqu'il emprunte, sans l'approbation d'aucun maître mais 
avec le sentiment d'une impérieuse nécessité, un chemin inconnu, un chemin creusé d'ornières mais qui lui semble, envers et contre tout, constituer le sien propre et le seul, un chemin dont personne au monde ne peut le détourner et dans lequel il s'engage avec la secrète intuition, que ce choix sera décisif : le chemin qui mène à la Haute École des marginaux et des pauvres, la Haute École des fous, la cité de Scherzhanserfeld, quartier de terreur absolu de la ville.

Et c'est un demi-tour salvateur. Car dans la cité Scherzhauserfeld où désormais il travaille, les gens n'ont pas peur d'appeler les choses par leur nom, les gens parlent ouvertement, franchement, sans les détours, sans la prudence, sans les pudeurs, sans la pondération et sans les fioritures propres aux discours bourgeois ; ils parlent ouvertement de choses essentielles comme l'alimentation ou la guerre qui est loin d'être terminée. Et pour le narrateur cette expérience constitue en quelque sorte une école de la vérité, cette vérité pourtant si difficile à dire. Maintes fois, tous nous relevons la tête en croyant qu'il nous faut la dire la vérité ou la vérité apparente et nous la rentrons de nouveau dans les épaules.

Mais si le narrateur de La Cave se réjouit de ce franc parler, il est loin d'idéaliser ces hommes et ces femmes qui se rendent dans l'épicerie de Karl Podlaha où il travaille désormais volontairement comme apprenti. Toute idéalisation d'ailleurs lui répugne. Toute idéalisation répugne à Thomas Bernhard, qui n'est que l'autre nom du mensonge. Il constate que, dès leur enfance, ces hommes et ces femmes de la cité Schezhauserfeld ont appris à haïr et à haïr au plus haut degré. Il constate qu'ils n'ont de cesse d'accuser Dieu, le monde et eux-mêmes de leur déchéance, juste, dit-il, pour pouvoir respirer. Il constate qu'ils ne poursuivent qu'un but c'est de s'autodétruire et de se détruire mutuellement. Ils se réfugiaient dans des chimères qui n'étaient en fin de compte 
que des cauchemars, dans des dettes qui les menaient en prison par le plus court chemin, dans l'exaltation de leurs imaginations d'où ils restaient comme assommés. Ils se réfugiaient dans des rêves, des fantasmes qui les affaiblissaient à mort. Eux, les habitants de l'antichambre de l'enfer, qui en vérité fut l'enfer, étaient toujours frustrés de toutes leurs possibilités, c'était leur nature de n'avoir aucune possibilité sinon celle de couler par le fond.

Thomas Bernhard, par les yeux de son double, observe la cité Scherzhauserfeld avec cette faculté d'intense observation qu'il a apprise, dit-il, de son grand-père, et il y apprend ce qu'il appelle la réalité absolue, c'est-à-dire la réalité la plus crue, la plus violente, la plus désespérante, la plus insupportable, celle qu'on voudrait absolument ignorer, celle qui n'a rien de romantique, celle que la plupart du temps on s'emploie à dénier parce qu'elle dérange trop violemment notre confort moral.

Rarement cette réalité absolue a été dite avec cette absence totale d'édulcoration, cette absence totale d'enjolivement, cette absence totale de fard, cette rudesse, cette cruauté aurait dit Artaud.

Rarement la misère des pauvres, leur détresse, leurs naufrages, leur absence désespérante d'avenir ont été observés avec cette implacable et terrible frontalité.

Rarement la violence qu'ils subissent dès leur naissance et ses irrémédiables effets ont été dits avec des mots de cette force.

Puissent-ils encore nous ouvrir les yeux. Avant qu'il ne soit trop tard. 


\section{Lydie Salvayre}

\section{Projet en cours}

\section{[Ces deux textes sont extraits de Marcher jusqu'au soir.]}

Je détestais depuis longtemps tous les dévots de l'art. Je les détestais pour avoir vérifié trois cent fois que le prurit culturel qui leur démangeait l'âme ne les rendait pas meilleurs que les autres, ni plus humains, ni plus dignes, ni plus justes, ni plus éclairés, ni plus intelligents, ni plus rien, que parfois même ils étaient de gros cons, de gros cons confits en connerie, de gros cons d'une connerie insolente, de gros cons émerveillés d'eux-mêmes qui paradaient aux vernissages et se pâmaient devant le dernier artiste à la mode, lorsque c'était le tour d'Armand Étienne, ils n'en avaient que pour Armand Étienne, qu'il était ci qu'il était ça qu'il faisait fureur qu'il était tout simplement génial, puis du jour au lendemain ils n'en causaient plus du tout, à la trappe !, et ils passaient au suivant avec le même enthousiasme, de gros cons présents à toutes les manifestations officielles de la culture où ils distribuaient des poignées de mains, ânonnaient pieusement leur haute conception de l'art, et faisaient leurs importants avec des phrases culturelles, des regards culturels,

Published in Lydie Salvayre, maintenant même, ed. Warren Motte (Lincoln, NE : Zea Books, 2021). doi: 10.32873/unl.dc.zea.1284 
une voix culturelle et, plaqué sur leur face un air discrètement supérieur de gros cons, de gros cons encore plus cons que ces cons de kangourous, de gros cons dont il fallait se tenir à distance prudente sous peine d'être éclaboussé par leurs très culturels et très élégiaques postillons, de gros cons après le passage desquels il était recommandé de procéder à une rapide désinfection par la Bétadine alcoolique à $5 \%$ pour les parties du corps exposées et par le Percarbonate de soude pour la contamination des lieux.

J'avais du reste constaté depuis longtemps que ma mère, qui n'avait jamais mis les pieds dans un musée, ni dans une librairie, ni dans une galerie d'art parce qu'elle avait le sentiment que cette culture-là ne la concernait pas et que, de plus, elle y aurait été regardée comme un élément étranger, comme une tache, comme une Arabe, ma mère qui n'avait jamais pratiqué aucun art hormis celui de coudre et de repriser les chaussettes de mon père, ma mère avait le cœur et la raison bien plus dignes et généreux que la plupart de ceux que Baudelaire non sans raison appelait la canaille artistique. Lorsque d'autres que moi avancent ce genre d'arguments, je me récrie aussitôt et me fâche tout noir, je crie au poujadisme, à la haine de l'esprit et à la haine du beau, et rétorque aussi sec que tout ce qu'ils ne peuvent concevoir : ils le rabaissent, et tout ce qui les déroute : ils le dénigrent amèrement.

\section{2}

Par je ne sais quel enchaînement d'idées, le souvenir de cette soirée bourgeoise en appela un autre : le souvenir des promenades du dimanche à Auterive avec ma mère dans le quartier des villas qui nous faisaient rêver parce qu'elles possédaient un jardinet, une balançoire, des rosiers grimpants à roses rouges et des noms de baptême tels que Les 
Charmettes, Les Pitchounets, La Niche, Au Bon Accueil ou Chez Poupette.

Ma mère et moi nous arrêtions devant chacune d'elles pour les admirer à loisir et nous apercevions derrière les volets les meubles imposants d'une pièce appelée salon. Alors nous rêvions tout haut d'habiter un jour l'une de ces demeures, avec un balcon fleuri peut-être, ou peut-être une véranda et une piscine de $10 \mathrm{~m}$ sur 5 avec des lauriers roses tout au long de la haie, et dans ma chambre-je le précisai à chaque fois - un lit à baldaquin. Et nos rêves, nos confabulations, nos plans sur la comète faisaient partie intégrante de nos vies, au même titre exactement que ce qu'on appelle la réalité, je pense même aujourd'hui qu'ils en étaient le cœur. Nous rêvions tout haut d'une autre vie, plus aisée, plus suave, plus musicale, plus veloutée, plus moelleuse, plus caressante, une vie plus considérée proposait ma mère, une vie qui viendrait adoucir l'âpreté du présent et où j'achèterai en boutique des pantalons à pattes d'éléphant c'était la mode, mais surtout une vie sans mon père me disais-je en moi-même, une vie où je n'aurais plus à subir ce dictateur me disais-je en moi-même.

Venait le moment où immanquablement je demandais à ma mère quand est-ce qu'elle prendrait la décision salutaire, je disais même la décision médicale, de divorcer d'avec mon père, je disais parfois d'avec Staline, et d'épouser Monsieur Aznar lequel avait une épicerie bien achalandée rue de la République et des perspectives d'avenir autrement plus radieuses, en tous cas moins accablantes et tempétifères que celles qui menaçaient l'horizon paternel. Alors ma mère me disait callate! no digas esas tonterias! tout en se retenant de rire, et nous continuions notre promenade le long du Chemin Saint-Loup, tout à nos songes. 


\section{Lydie Salvayre}

\section{Quatre photos}

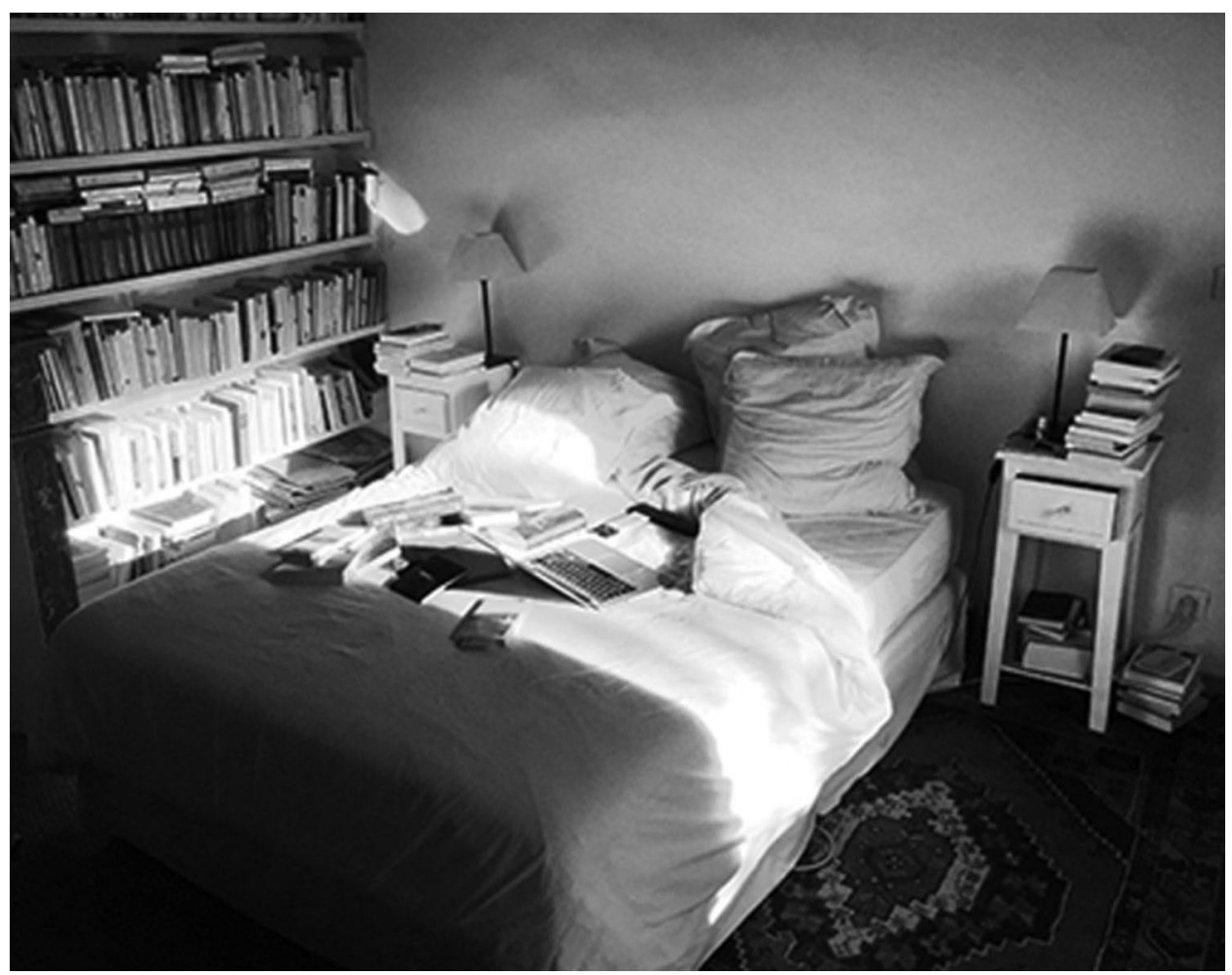

«Au fond je suis un sportif, le sportif au lit. »

- Henri Michaux

Published in Lydie Salvayre, maintenant même, ed. Warren Motte (Lincoln, NE : Zea Books, 2021). doi: 10.32873/unl.dc.zea.1285 
QUATRE PHOTOS

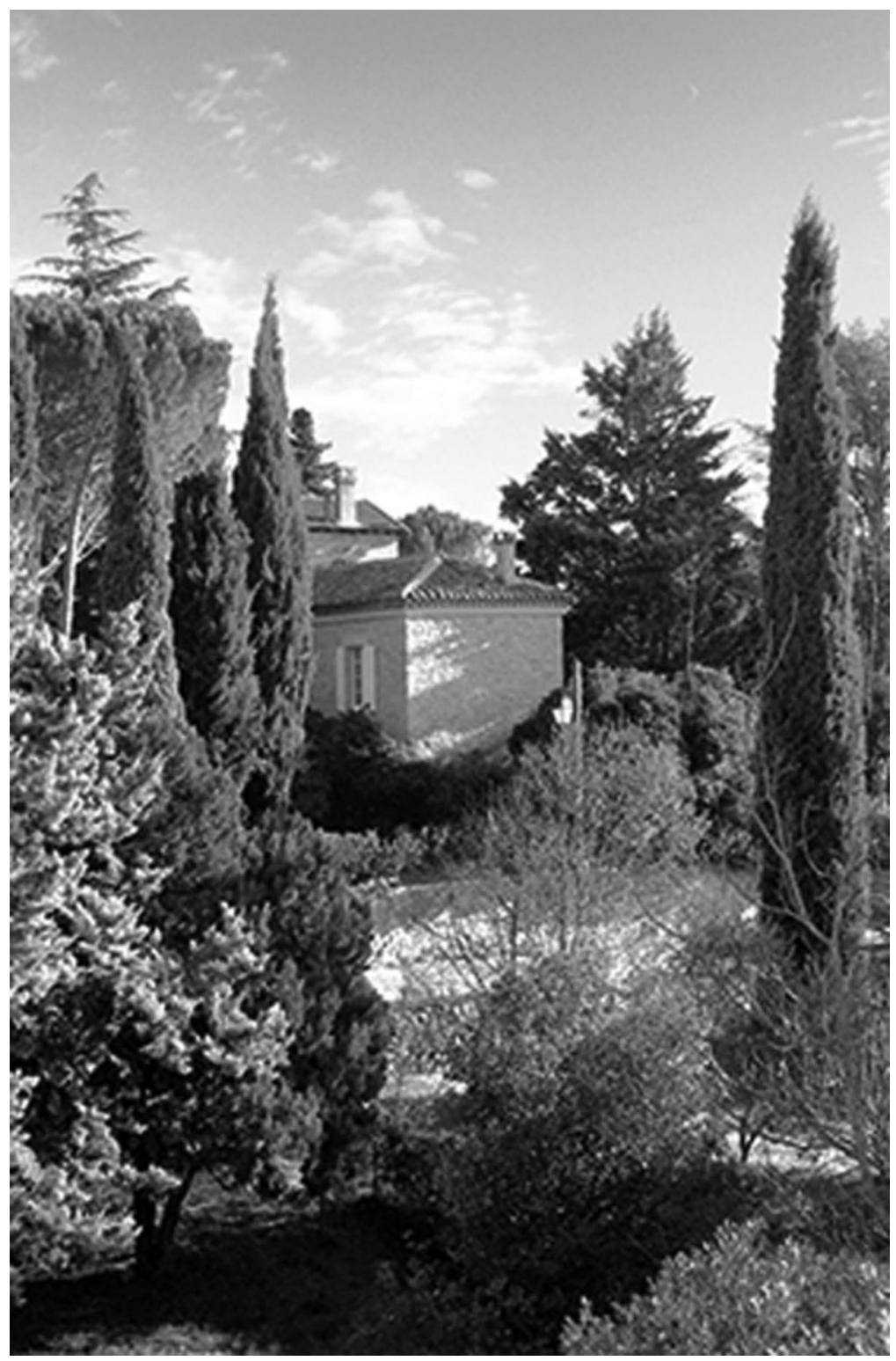

Chambre avec vue 
LYDIE SALVAYRE

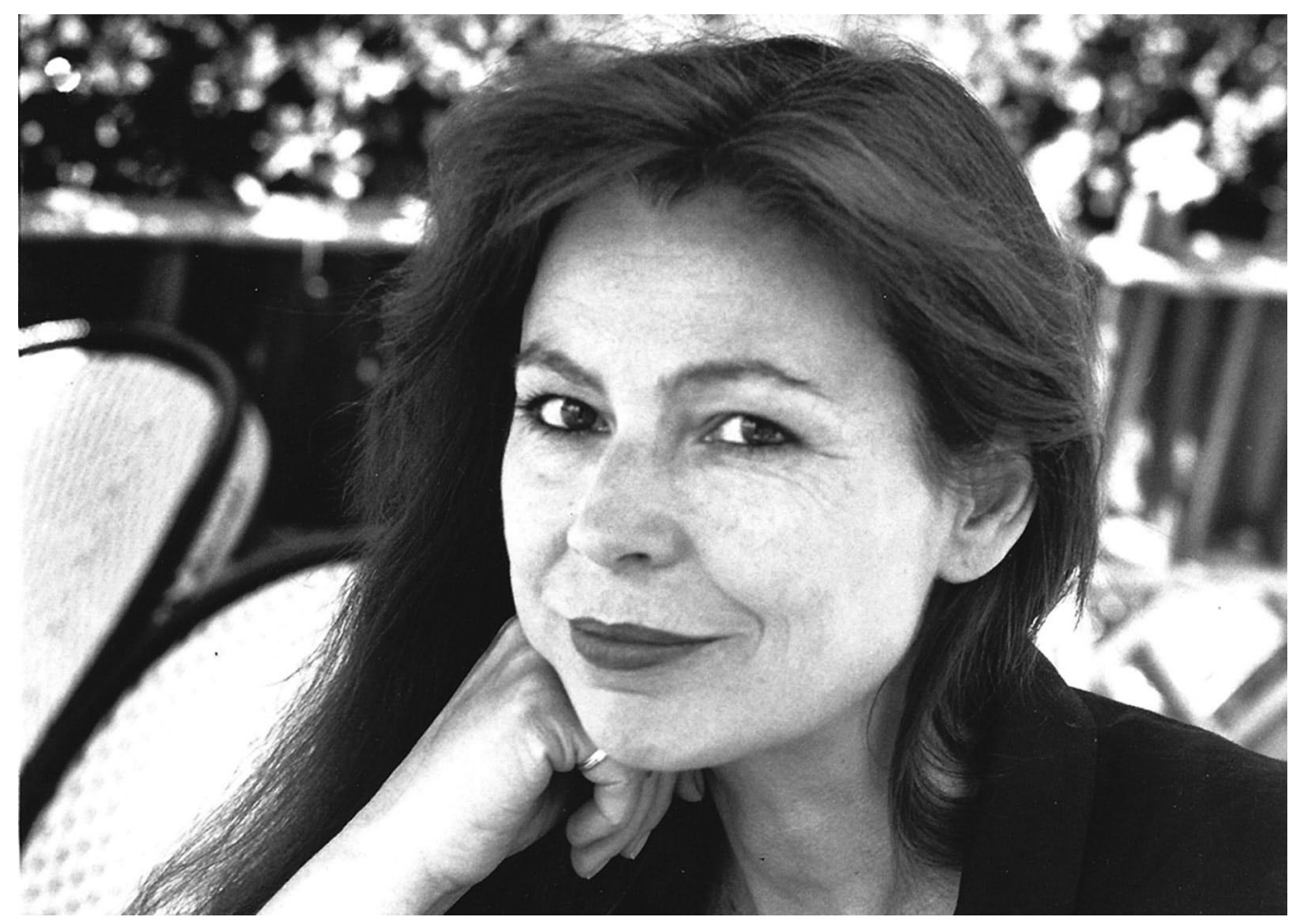

Lydie Salvayre - Paris - Mai 2013 
QUATRE PHOTOS

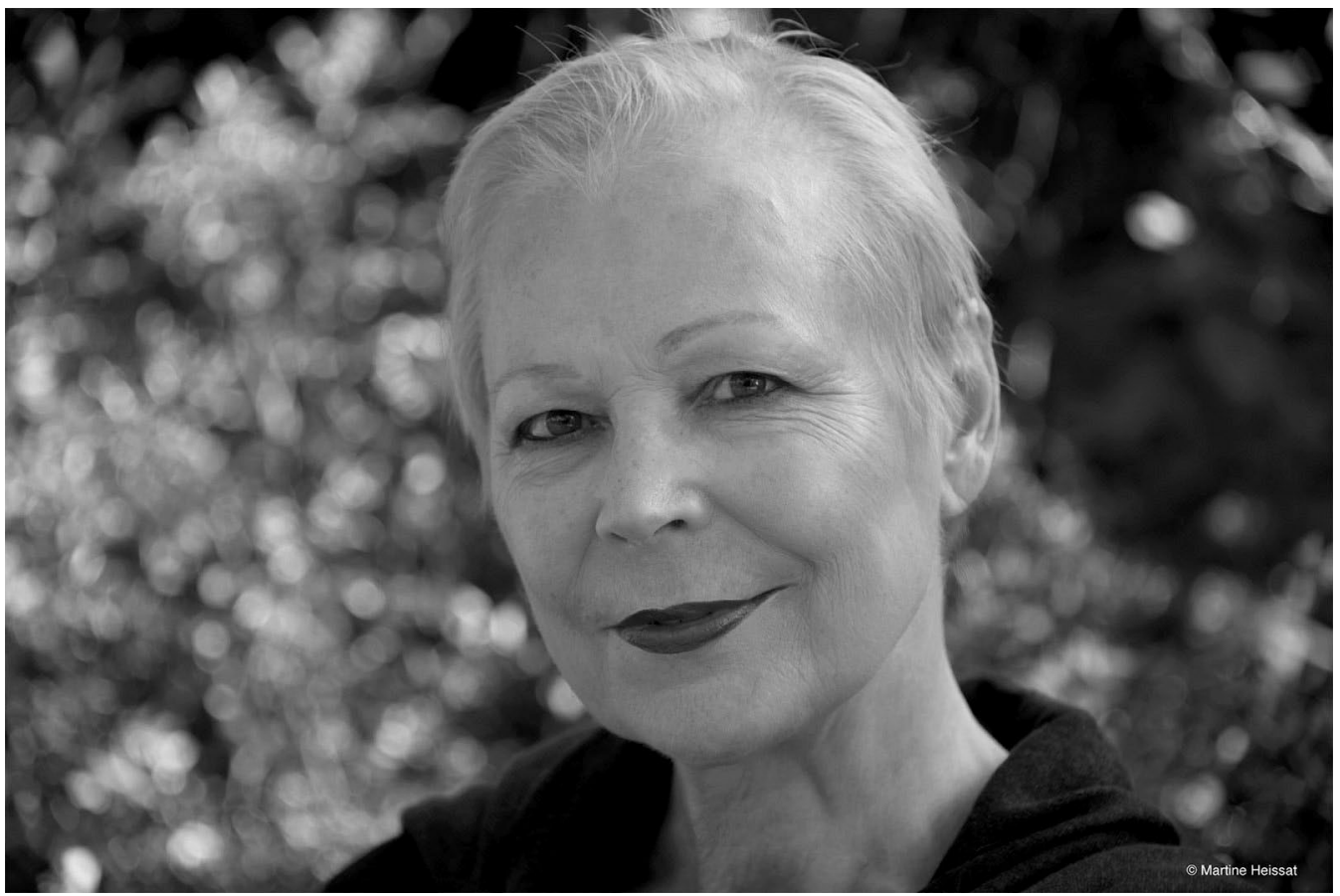

Lydie Salvayre - Le Pin - Juin 2018 


\section{Lydie Salvayre, écrivain baroque'n'roll}

Dès sa petite enfance, Lydie Salvayre parle deux langues. À la maison, elle parle l'espagnol qui est la langue de ses parents, réfugiés politiques dans le sud de la France suite à la prise de pouvoir de Franco. À l'extérieur, elle parle le français.

L'espagnol va devenir la langue du dedans, la langue de l'intime, des ripostes intérieures, la langue qui prend en charge tout ce que ne peut porter la langue du dehors, tout ce qui par elle est laissé de côté, tout ce qui est excessif, tout ce qui déborde, tout ce qui ne peut se rendre public, tout ce qui n'a pas d'existence légale.

Le français, parallèlement, va incarner pour Lydie Salvayre la langue de l'école, la belle langue des livres, la langue contrôlée, parfaite, impeccablement grammaticale. La langue après laquelle elle court, après laquelle elle ne va cesser de courir et qu'en amoureuse elle ne va pas cesser de désirer.

Elle le dira d'ailleurs elle-même lors d'une conférence ${ }^{1}$ :

" Je crois que c'est, justement, ce désir tenu en échec de maittriser une langue, je crois que c'est ce point de

${ }^{1}$ Les extraits des conférences ou interventions de Lydie Salvayre en France ou en Europe seront donnés en italique au cœur de ce texte.

Published in Lydie Salvayre, maintenant même, ed. Warren Motte (Lincoln, NE : Zea Books, 2021). doi: 10.32873/unl.dc.zea.1286 
faillite auquel j'ai fini, un jour, par consentir, je crois que ce sont ces conditions malaisées d'apprentissage du français qui ont exigé de moi, plus tard, le recours nécessaire à l'écriture. Pour le dire avec d'autres mots, je crois que si je m'étais senti propriétaire d'une langue, dans une adhérence parfaite et parfaitement climatisée à une langue et à une histoire, je crois que je ne serais jamais advenue à l'écriture. Je dis : je crois. Car ce ne sont là évidemment qu'hypothèses. Donc, et je ferme la parenthèse, deux langues : l'une qui m'a en quelque sorte bercée dès la naissance, l'autre que je désire d'autant plus fort qu'elle m'échappe.

Je croyais jusqu'ici que ma singularité d'écrivain tenait à cette "nage entre deux rives », pour reprendre la belle expression de Chateaubriand, à cette nage entre la rive classique qui est pour moi, éminemment française, et la rive baroque que j'identifie, pour mille raisons à l'Espagne de mes origines ».

Dès le début, ces deux langues en elle vont entrer en guerre.

Et cette guerre va s'aggraver du fait que, tout en découvrant la littérature espagnole baroque, Lydie Salvayre se prend de passion pour les grands classiques français.

Divisée donc entre, d'un côté, son attirance pour le baroque espagnol dont Francisco de Quevedo incarne, à ses yeux, la figure exemplaire :

«Quevedo est le plus baroque des écrivains baroques. Auteur excessif en tout, excessif dans l'irrévérence, excessif dans la satire, excessif dans la caricature, excessif dans sa volonté comique, excessif dans la virtuosité de la langue, dans les jeux et les détournements qu'il fait subir 
aux mots, et dont l'outrance littéraire contraste violemment avec la sagesse des lectures que j'ai faites jusquelà. Quevedo, l'aristocrate, qui met en scène dans « El Buscon » des tableaux hallucinés où s'agitent des picaros, des voyous, des filous, des poètes de caniveau, des nobles de pacotille, des mendiants en haillons, toute une humanité misérable, toute une galerie de marginaux comme on peut les trouver chez Céline, et qui se livrent aux actions les plus basses et aux escroqueries de toutes sortes, Quevedo dont le baroquisme échevelé me semble mieux rendre compte de ce qu'est ma vie à ce momentlà, puisque c'est encore la période où la communauté espagnole émigrée en France est très resserrée, où les dimanches réunissent une trentaine de personnes autour d'une table, où ça parle fort, où ça jure, où ça plaisante, où ça trucule, où ça s'enflamme ».

Bien que très attirée par le baroque, Lydie Salvayre éprouve une passion égale pour la perfection, la pureté, l'économie, la rigueur, l'élégance de la langue classique française, une langue débarrassée des tournures populaires et des scories baroques, expurgée des irrégularités, des injures, des blasphèmes, des grossièretés, des trivialités, « une langue émasculée » dira violemment Céline dans un entretien. Une langue, en tout cas, excessivement claire, mesurée, simple, lisible et suspicieuse de toutes les outrances comme l'est la langue de Blaise Pascal pour laquelle Lydie Salvayre témoigne de son amour dans La Puissance des mouches.

Ces deux langues extrêmes (l'une dans l'outrance, l'autre dans la rigueur) vont chez Lydie Salvayre être constamment en conflit. Ou plus subtilement, vont être en état de guerre permanent : cette part du français qu'elle appelle 
l'espagnole (celle qui prend en charge les irrégularités, les inconvenances, tous les écarts, et grâce à laquelle elle fera sa « pédagogie du vertige »), et cette autre dite classique (qui est la part parfaite, la part maîtrisée, le grand goût, le grand genre, la langue du bien-dire, qui est tout sauf un dire moyen, qui est tout sauf une langue moyenne, qui est même l'une des façons de rompre avec cette langue moyenne dont nous sommes abreuvés et qui lui fait horreur, une extrême langue portée par un extrême esprit [extrême esprit dont Pascal disait qu'il était considéré comme fou tandis que la médiocrité était considérée comme bonne]).

Une guerre donc entre deux langues. Mais une guerre amoureuse. Une guerre qui va féconder cette « entre-deux rives » une langue qui va tenter sans cesse de faire cohabiter le classique français et le baroque espagnol : des passages, des combinaisons, des glissements et, quelquefois, des collisions.

Pour le dire autrement, Lydie Salvayre va faire de cette passion contradictoire pour ces deux langues, SA langue. Elle va littérairement apprendre à nager entre deux rives.

La rive du classique qui chez Lydie Salvayre n'a rien à voir avec la fadeur avec laquelle souvent on le confond, qui n'a rien à voir avec le prêt-à-lire, la rive classique qui est la rive de la phrase tendue comme la corde d'un arc, de la phrase acérée, tranchante, de la ligne dépouillée, qui est la rive de la mesure et de l'absolue élégance, mais qui risque de s'anémier à force de perfection.

Et la rive baroque, rive du tourbillon, ou de la volute ou du vertige, une forme en tout cas qui rappelle l'intérieur des églises sévillanes : foisonnement, surabondance, méandres, expansion sans fin, mais qui peut flirter ou dégénérer en kitsch à force de surcharge. 
Tout son travail d'écriture va chercher à réconcilier ces deux parts en elle.

Tout son travail d'écriture va consister à marier la pureté classique avec l'impureté baroque, le langage le plus châtié avec le plus commun, les phrases en alexandrin avec les plaisanteries d'un goût discutable.

Le meilleur exemple qui puisse être donné de ce mariage contre-nature entre classique et baroque est l'usage que Lydie Salvayre fera dans « La Méthode Mila avec la conjugaison à l'imparfait du subjonctif du verbe niquer ».

Marier la carpe baroque avec le lapin du classicisme, marier le sublime et le trash, le tragique et le comique, la violence et la mesure, l'élégance racée de l'écriture pascalienne et l'archi-mauvais goût quévedien.

Mauvais goût car c'est ainsi que le baroque est défini dans le vocabulaire esthétique du XVIII siècle français.

Rousseau, par exemple, écrit :

« Les fugues, contre-fugues, doubles fugues, fugues renversées, basses contraintes et autres sottises que l'oreille ne peut souffrir et que la raison ne peut justifier, sont évidemment des restes de barbarie et de mauvais goût qui ne subsistent, comme les portails de nos églises gothiques, que pour la honte de ceux qui ont eu la patience de les faire ».

Quant à Voltaire, il affirme que le goût baroque relève de la plus honteuse barbarie, à la différence du goût classique qui lui relève du grand goût.

Il est intéressant de faire un petit détour historique pour comprendre les positions esthéticomorales de ces deux prestigieux auteurs français.

Le baroque en littérature, et on le voit bien chez un 
écrivain comme Quevedo, est qu'il dit tout et sous toutes les formes disponibles. Tout, c'est-à-dire aussi bien le noble que l'ignoble, aussi bien le bas que le haut, aussi bien le sublime que le vulgaire (en prenant au passage le soin de préciser qu'étymologiquement le vulgaire désigne ce qui est commun à tous).

Le classique, en revanche, manifeste, lui, le souci de se distinguer absolument du vulgaire, de s'arracher aux choses sordides, de nier l'animalité en l'homme, d'associer à la rigueur morale une sobriété des moyens, une simplicité, une clarté qui ne peuvent que rejeter et condamner les débordements baroques.

On pourrait aller jusqu'à dire que ces deux catégories que sont le classique et le baroque recoupent deux conceptions morales et esthétiques du monde, voire même deux positions politiques.

Certains ont soutenu, en effet, que la langue classique était-originairement-politique puisqu'elle naissait en 1635 avec la fondation par Richelieu de l'Académie Française dans le souci d'instaurer une langue guidée par la raison, une langue susceptible d'accroître le prestige royal, une langue nettoyée de tous les particularismes pour devenir la langue universelle, purifiée de tous les dérèglements langagiers qui avaient précédé (et dont Rabelais avait été l'un des champions, Rabelais qu'on allait désormais trouver grossier).

Avant de poursuivre, il faut revenir sur cette notion de mauvais goût, tel qu'il est pratiqué chez Quevedo et chez un artiste comme Picasso.

Picasso affirmait qu'il fallait absolument, pour devenir grand peintre, cultiver le sublime autant que le mauvais goût, mais le mauvais goût conscient de son mauvais goût, le mauvais goût délibéré, le mauvais goût qui naît d'une 
jubilation à passer les bornes, d'un refus de la mesure et la norme, ajouté au plaisir dandy de déplaire ou de choquer.

Mauvais goût de Rabelais, de Céline, de Carlo Emilio Gadda, d'Antonio Lobo Antunes ... autant d'auteurs qui sont dans le régime du trop, trop riche, trop outré, trop satirique, trop appuyé.

Mauvais goût qu'il faut impérativement distinguer du mauvais mauvais goût, celui qui s'ignore, celui qui est précisément le goût moyen, le goût prudent, qui préside à la télévision notamment, celui du pseudo savoir, celui des auteurs pontifiants, de ceux-là qui s'acharnent à dénoncer précisément le mauvais goût chez l'autre et à stigmatiser la surcharge et l'inflation.

Cette langue chez Lydie Salvayre qui cherchait son chemin entre le classique et le baroque est devenue sienne au fil de ses livres. Et c'est avec sa langue « baroque n'roll » que l'écrivain « fragnole » va aborder les thèmes qui sont les siens. On peut en faire émerger quelques-uns dans son œuvre comme celui-probablement le plus récurrent-de l'exil.

Rose Mélie la folle de La Compagnie des spectres, Olympe la muette des Belles Âmes, le philosophe raté de La Méthode Mila sont autant de figures de l'exil, de l'exil intérieur, et sans aucun doute la conversion romanesque des expériences de l'exil que vécurent la mère et le père de Lydie Salvayre en quittant l'Espagne en 1939, et surtout du double exil de son père, qui à l'exil affectif lié à sa rupture définitive avec sa famille restée en Espagne (famille qui appartenait à la grande bourgeoisie andalouse et franquiste) ajouta l'exil social que constituait pour lui le fait de travailler comme ouvrier en France. 
Le thème de la paranoïa qui apparaît surtout dans La Vie commune et en filigrane dans d'autres livres, et qui apparaît pour des raisons clairement biographiques puisque le père de Lydie Salvayre, pour contrer le malheur de ce double exil social et affectif avait développé une sorte de délire de persécution qui avait fini par le conduire à l'hôpital psychiatrique.

Le paranoïaque, c'est celui qui recherche désespérément du sens. Et dans cette mesure, il est un peu écrivain, puisqu'il introduit sans cesse entre lui et le monde, une fiction productrice de sens.

Le paranoïaque hausse jusqu'aux extrêmes cette exigence de donner un sens clair et lisible à la vie et au monde, exigence qui est d'autant plus forte, d'autant plus exacerbée, d'autant plus tyrannique que le monde se présente comme incohérent, chaotique, insensé et dangereux.

"Il me semble parfois que c'est une forme de paranoïa qui est au principe de mon geste d'écrire, le désir de donner une raison aux choses, de m'insurger contre un état du monde, de pointer les causes du mal, d'écrire contre tout l'inadmissible du monde, contre la bêtise du monde, d'écrire par exemple contre les gendelettres, bref toutes ces choses que je ne peux m'empêcher d'écrire même si elles me font un tort certain.

Mais, mais j'éprouve en même temps, le désir égal d'affirmer le non-sens des choses, l'incompréhensible " qui ne cesse pas d'être » comme le disait mon cher Pascal, la beauté de l'accident et du hasard, le pur plaisir d'écrire dénué d'intention, le pur plaisir du rythme, le pur plaisir de la flûte comme aurait dit Céline, le pur plaisir de jouer juste au sens musical du terme.

J'ai l'impression, sur ce point encore, de nager entre deux rives, l'une sensible au monde, à l'homme dans le 
monde et cherchant à saisir " les orties de la réalité 》 selon la formule d'Arno Schmidt, et l'autre cherchant une forme, un déploiement, un contour, l'autre sensible au rythme, au flux, à la sensualité des mots ».

Pour en revenir à La Vie commune et à la paranoïa, Suzanne, le personnage central, est une femme qui a trouvé un sens à son malheur en se trouvant une ennemie. Ruse paranoïaque s'il en est, très répandue du reste, pour ne pas dire banale. Cette ennemie est-elle imaginaire ou réelle ? On ne le saura pas. L'important n'est pas là. L'important, est que, comme souvent chez les paranoïaques, le délire de cette femme a une puissance d'élucidation formidable puisqu'il met à jour une vérité qui est de taille. Il met à jour la bascule définitive qui s'est opérée dans le monde du travail où la rage de la rentabilité a supplanté, désormais, la morale.

En se drapant d'éthique, comme elle le fait, en s'acharnant à demeurer vertueuse quand elle devrait se montrer performante et tout occupée de stocks options, Suzanne signe son inadéquation totale à la vie de bureau, et au monde qui est en train d'advenir. En cherchant nostalgiquement dans le travail un lieu où s'épanouir et s'élever, elle témoigne d'un attachement à une idéologie désormais caduque.

Ce thème du travail abordé dans La Vie commune, on va le retrouver dans La Médaille et dans La Puissance des mouches, le travail vécu non pas comme lieu d'épanouissement et d'émancipation, mais comme lieu de violence et d'écrasement, un lieu où l'être est séparé de lui-même, absent à lui-même.

Puisque nous évoquons La Vie commune et La Puissance des mouches, dans ces deux romans, le lien parent-enfant est difficile, pour ne pas dire belliqueux, façon pour Lydie 
Salvayre de s'en prendre aux idylles familiales, façon pour elle de rendre compte de ce qu'elle n'avait cessé de constater dans le cadre de ses consultations comme pédopsychiatre, à savoir que les rapports familiaux étaient des rapports de pouvoir, motif qu'elle va reprendre dans presque tous ses romans. La famille comme inépuisable expérience d'une violence et d'une oppression que l'on va rejouer, plus tard, avec d'autres. La famille comme stage d'apprentissage de la soumission. La famille comme lieu de la guerre.

Un thème important et que l'on retrouve dans tous ses livres est celui du corps, le corps concret, le corps charnel, le corps qui souffre et qui jouit, le corps dans toute sa crudité et dans tous ses états, le corps pantelant et infirme de la vieille mère dans La Méthode Mila, le pauvre corps sexuel et maltraité d'Olympe dans Les Belles Âmes.

« Corps dont la présence est directement liée, j'en suis sûre, à mon expérience d'interne en médecine (c'est une chose que l'on retrouve chez Rabelais et Céline qui étaient tous deux médecins) puisque, en tant que médecin, je me suis trouvée devant cette situation inouïe : celle d'un accès au corps nu de l'autre sans avoir à détourner le regard, sans faux-semblant, sans jugement moral et encore moins esthétique, dans un rapport direct, frontal, dans un rapport dont je me plais à penser qu'il m'a en quelque sorte exercé à regarder les choses en face, la beauté comme la hideur ».

Et puisque l'on aborde la beauté et la hideur, ces deux termes renvoient à un thème qui revient souvent dans les livres de Lydie Salvayre : celui de la littérature comme héritage. 
"C'est que l'on écrit toujours avec un héritage. Et que cet héritage, en quelque sorte, m'écrit. Mais cet héritage, parfois, est un poids. Il existe trop. Il se manifeste trop. Et ce que je redoute sans cesse, c'est qu'il se manifeste à mon insu, c'est qu'il se reproduise à mon insu, c'est que je fasse des citations mais sans le savoir ».

L'intérêt est évidemment de jouer de cet héritage, mais en le revisitant, en lui apportant du sang neuf, en posant, pour paraphraser G. C. Lichtenberg, « un regard neuf à travers de vieux trous », en le déplaçant par exemple dans un contexte contemporain, ou en le réécrivant. Dans La Compagnie des spectres, si certaines citations d'Épictète ou de Caton sont littérales (l'intérêt étant de montrer combien elles gardent leur validité dans le présent, combien elles sont anciennes et contemporaines en même temps), d'autres sont totalement réécrites et d'ailleurs peu nombreux furent ceux qui s'en aperçurent.

Dans La Puissance des mouches, Lydie Salvayre va aller plus loin avec cet héritage littéraire, puisqu'elle va faire des Pensées de Pascal le personnage central de son roman.

La Puissance des mouches est la rencontre, que l'on peut définir comme amoureuse, d'un homme et d'un livre.

L'histoire d'un lecteur mais du lecteur idéal, d'un lecteur créateur. Puisqu'il n'y a pas un seul événement dans sa vie quotidienne qui ne le renvoie à cette lecture.

Les Pensées de Blaise Pascal sont pour lui ni matière à citations, ni matière à étalage, ni sujet de débat dans les dîners mondains, mais objet de désir, machine à créer, à penser, à se souvenir, à vivre. Le livre n'est en rien pour lui une chose pasteurisée, dévitalisée, que l'on range dans une bibliothèque. Il n'est pas lettre morte, mais lettre vive, vivante, ludique, dynamique, qui ne le laisse jamais indemne, qui va 
lui permettre de lire sa vie autrement et le faire naître, d'une certaine manière, à la parole.

La plupart les personnages des livres de Lydie Salvayre sont en colère. Ils « l'ouvrent » comme on dit « vulgairement ».

Rose Mélie de La Compagnie des spectres est en colère, le narrateur de La Puissance des mouches est en colère, celui de La Conférence de Cintegabelle est en colère comme celui de La Méthode Mila est en colère, $B W$ est en colère.

Cette colère remue les personnages de ses romans. Et ce qui est stupéfiant, c'est que Lydie, qui ne se met quasiment jamais en colère dans le quotidien (je le sais puisqu'elle est ma compagne de vie), ou plus exactement qui semble n'en éprouver qu'exceptionnellement le besoin (rires), voit sa colère se réveiller dès lors qu'elle fait le geste d'écrire. C'est étrange. C'est inexplicable. Et elle en est toujours la première surprise.

" J'ai même le sentiment parfois que cette colère s'exerce sur mon écriture même, qu'elle cogne la phrase, qu'elle cloue la ponctuation, qu'elle déchire comme disent les jeunes avec les mots comme des haches pour reprendre la métaphore de Sylvia Plath dans Ariel.

Mais c'est une colère qui s'habille la plupart du temps d'ironie, en tout cas je l'espère, et se résout, je l'espère aussi, dans le rire?» 


\section{David Lopez}

\section{Almuerz}

Elle m'a laissé le choix. Salsa amarilla o roja, avec les albondigues. J'ai dit amarille, abuela, c'est ce que je dis à chaque fois qu'elle me pose la question. Bueno elle a répondu, le sourire dans la voix, satisfaite à l'idée de satisfaire, et puis elle a ajouté que nunca elle s'accorde de ce que moi je préfère, parce que mi hermano también il a ça qu'il aime, et puis il vient plus souvent alors parfois elle se confond. Mais c'est vrai qu'on la laisse cociner, comme elle dit, et qu'elle connaît nos préférences, sachant qu'en général on aime bien quand ça se mange à la cuillère. Mais pour les albóndigas, l'exception n'a rien d'une gageure. Quand je lui demande si elle a besoin d'aide je sais déjà qu'au final je ne vais rien faire du tout, puisque je n'ai pas fini ma phrase que déjà elle me dit no no no, siéntate, si toi tú m'aides c'est cuando se termine, pa rebañar, et elle rit en retirant son tablier à toutes petites fleurs. D'accord, abuela.

Un rayon de soleil inonde la moitié de la table, que le store occulte à peine en cette position. D'ici on voit la montagne au loin, et je n'ai qu'à la regarder quelques secondes pour qu'elle me parle del abuelo, toujours assis là, sur la fin, à regarder cette montagne, en vanter les beautés et les avantages qu'il y a à rester là, assis sur cette chaise, à la contempler. Il

Published in Lydie Salvayre, maintenant même, ed. Warren Motte (Lincoln, NE : Zea Books, 2021). doi: 10.32873/unl.dc.zea.1287 
ne voulait plus vivir, me dit-elle comme si c'était la première fois. Quand son état s'est dégradé, le premier virus passé lui a quitté la vie. Mais c'est meilleur comme ça, elle ajoute en regardant dans le vide, et puis elle reprend sa contenance, pose sa main sur mon bras avec dépit, esta lista la comida, quedate à table yo arrive.

Je n'ai manifestement pas été convaincant quand j'ai dit que j'en avais assez dans l'assiette. C'est pas trop chaude? elle demande, en soufflant sur sa fourchette, et je dis esta bien, en soufflant aussi, pour l'imiter. À peine ça entre dans ma bouche que déjà je voyage dans le temps, cette saveur si familière de part son étrangeté, et puis je la regarde du coin de l'œil, avec le rictus en-dessous, je n'ai pas les mots pour exprimer le plaisir que je ressens alors on s'en tient à ce regard complice, qu'elle ponctue souvent d'un voilà, en s'apprêtant à attaquer l'assiette à son tour. Ça la met en joie comme ça n'a pas l'air non plus de la surprendre, et après quelques bouchées elle me pose la main sur le bras, et s'essuyant la bouche de l'autre main, elle me dit alors David, conta-moi, qu'est-ce qu'il t'arrive de nuevo, el libro qué tal, et je lui réponds que par-dessus tout j'aimerais avoir le temps d'écrire, que j'ai commencé quelque chose mais je navigue à vue, comme toujours. Pero tú trabajas verdad?, si abuela, bien seguro, comme on dit chez nous en fragnol. Ces derniers temps j'ai surtout rencontré mes lecteurs, ah bueno dit-elle avec enthousiasme, y esa gente ils disent quoi ? ils aiment ça que tú escrives ?, et je n'ai pas le temps de répondre qu'elle s'exclame que, de toute façon, ceux qui n'aiment pas c'est porqué ils ne connaissent rien de tout.

À la fin du repas elle me demande si je veux un dessert, et elle a beau savoir que je n'en mange jamais elle ne voudrait pas manquer la fois où, pour on ne sait quelle raison, j'en exprimerais le désir. Cafecito y ya, je dis, et la voilà partie vers 
la cuisine. Ces moments où elle s'absente pour s'affairer, autrefois, donnaient lieu à un tête à tête avec mon grand-père. Quand j'étais petit, c'était le moment propice à recevoir, pour moi, et dispenser pour lui, une leçon de vie. Souvent il me disait David, tú devois pas faire ça que tú devois pas faire, et j'ai mis du temps à comprendre qu'il me parlait de conformité à soi-même, de fidélité à ses principes, de tenir le cap qu'on s'est fixé. Ces dernières années, il semblait avoir renoncé à nous apprendre quoi que ce soit. Et ce tête-à-tête ne consistait plus qu'en une brève confession quant à sa lassitude envers la vie. Ces moments-là ne me manquent plus.

Alors qu'elle a déjà lavé les assiettes et tandis que le café coule, ma grand-mère revient s'installer à table, où je l'attends, dans un soupir. Elle approche sa chaise de la table ainsi que de moi dans le même geste, pose sa main sur mon bras. Bueno David, elle dit, et c'est quoi ça que tú escrives en ce moment alors? Je dodeline de la tête avant de répondre, elle sourit déjà, et je dis pas grand-chose abuela, pour l'instant j'ai peu de matière, je ne sais pas trop où ça va. Je lis, surtout. Ah bueno elle fait, et c'est quoi ça que tú lis aujourd'hui, et justement je saisis l'occasion pour lui parler de cette auteure, Lydie Salvayre, dont je me dis souvent qu'elle aimerait la lire.

Je lui raconte que la première fois que j'ai lu Lydie Salvayre j'ai été jaloux. Jaloux parce que le fragnol, d'abord. Depuis petit je connais ça le fragnol. On parle ça chez nous. On a notre propre lexique. On se foule le tobille, on a une écharde dans le ded, et la p'tite elle a des mocos. J'aurais voulu proposer ça, je dis à ma grand-mère, l'écrire en ne sachant pas qu'on l'a déjà fait avant, et ma grand-mère elle dit que c'est n'importa quoi ça que je dis, tú fais ça que tú veux, et je me rends à l'idée que pour ma grand-mère je n'ai qu'à faire quelque chose pour en être l'inventeur. 
Comme toujours j'ai demandé si je pouvais fumer et comme toujours elle m'a dit oui. Évoquer la guerre d'Espagne ça conduit systématiquement ma grand-mère à me parler de ces hommes qu'on libérait de prison et qu'on exécutait à la sortie, et de cet oncle, livré à ce sort, qui avait pu prendre un tram qui passait pile à ce moment-là. Elle est née pendant, ma grand-mère. Elle me raconte les souvenirs qu'on lui a laissés, et m'en laissera une partie. Je me suis déjà demandé si on m'avait tant parlé de cet oncle qui n'est pas mort à la seule fin de ne pas évoquer ceux qui le sont. Dans cet héritage qu'on me laisse, c'est de la vie qu'on me parle. C'est ce que je dis à ma grand-mère et j'ajoute tu vois abuela c'est ça, c'est ça qui m'a pris dans le livre, parce la meuf elle parle de la guerre avec sa mère et sa mère elle lui raconte quoi ?, elle lui raconte le plus bel été de sa vie !, la période où elle s'énamore, où elle est dans un genre de bouillonnement intellectuel, où elle s'émancipe. Parce que dans le livre, la guerre c'est pas le sujet, la guerre c'est le décor, un décor qui sert à faire ce que font les bons livres, raconter la vie. Sans artifice scénaristique ni posture idéologique. Et elle fait ça, elle, Lydie Salvayre, elle mentionne l'horreur, et puis elle te raconte la vie qui s'en accommode.

La fumée des cigarettes roulées accroche moins aux rideaux, pour ça qu'elle m'a laissé rester à table plutôt que m'approcher de la fenêtre. Je poursuis à propos de Salvayre, je dis que c'est ça qui m'intéresse justement, cette capacité à investir des sujets graves et d'en sacar la beauté, les traiter avec légèreté sans pour autant les vider de leur substance, sans que la menace ne s'éloigne, tapie tout près et prompte à changer le destin des personnages. Et tout ça sans pathos, mais comme ma grand-mère a un peu de mal avec ce mot je parle de misérabilisme, de cosa hecha para sacarte las lágrimas, de larmoyance donc, et j'ajoute que c'est un sacré 
numéro de funambule ce qu'elle propose, qu'elle est sans arrêt en équilibre sur une membrane, et qu'il s'agit d'avoir les chevilles souples. Ma grand-mère me dit pero quand même, c'est un sujet dur, como on s'impose une telle violence a sí mismo, toi aussi tú fais así David ?, et je ris, je réponds que oui, oui abuela, c'est une nécessité, qu'on le veuille ou non. Je lui cite le passage de Pas pleurer, très tôt dans le bouquin, où Salvayre parle du trouble que lui cause la jonction des récits de sa mère et de Bernanos, un trouble, dit-elle, dont elle craint qu'il ne l'entraîne là elle n'avait nullement l'envie d'aller. Car ce trouble implique d'envisager que les temps sombres n'empêchent pas la vie. Et que, pour instruit qu'on soit, on ne voit pas forcément venir. Ce trouble-là, c'est précisément où se situe le récit, dans ce va-et-vient constant entre atrocité et émerveillement. Et ça raconte quelque chose de l'endroit où se situe l'auteure, car je pense qu'on n'écrit jamais de choses aussi importantes que celles qu'on aurait préféré passer sous silence. C'est tout autant une tâche à accomplir qu'une responsabilité à assumer. Ainsi seulement le fardeau devient tremplin.

Le soleil a tourné un peu, c'est la table dans son intégralité qui est baignée de soleil maintenant. Ma grand-mère se lève pour baisser un peu le store, car j'ai le soleil dans les yeux. Quand elle se rassoie je reprends. Tu vois abuela, en fait Lydie Salvayre elle ne dit pas, elle montre, et ma grandmère se souvient m'avoir déjà entendu parler de ça. Je poursuis en insistant sur l'incarnation, oui abuela, encarnado sabes, ça permet de faire l'économie des discours, et puis ça caractérise de manière plus profonde et plus parlante les personnages. Après, c'est sûr que ça implique de montrer en deux pages ce qu'on pourrait dire en deux lignes. Mais ce qui est dit en deux lignes vit en moi le temps d'un chapitre, alors que ce qui m'est montré en deux pages vit en moi pour 
le temps du livre. Pour ça, ce qu'elle fait, c'est qu'elle utilise une écriture orale, où on entend les voix, les intonations, et d'un point de vue formel elle ne s'embarrasse même pas de la ponctuation, tu sais les guillemets et les tirets qu'on voit à chaque fois, non non, elle intègre la parole au récit. $\mathrm{Ma}$ grand-mère me fait remarquer que lorsque je parle de littérature mon débit s'accélère, alors j'essaie de m'adapter mais sur le coup je perds le fil, alors on rit ensemble. Siga, me interesa mucho lo que estas diciendo, me dit-elle. Alors j'en viens à dire que la grande force de Salvayre, à mon sens, c'est de toujours proposer un angle formel dans ses textes. Investir un sujet pour y raconter une histoire est une chose, mais se contenter de la chose racontée n'est pas suffisant. Chez Salvayre le quoi n'est pas une fin en soi, il est même une limite. Chez Salvayre, on sublime le quoi par le comment, ce qui implique que, peu importe ce qui est évoqué dans l'œuvre, c'est la littérature qui reste le sujet principal, et une réflexion sur celle-ci par la proposition esthétique. D'où le fait, d'ailleurs, que je perçois chez elle un rapport très ambivalent, duale, à l'écriture, car si son œuvre semble procéder d'une viscérale joie d'écrire elle paraît tout aussi réfractaire à la complaisance, en ce sens que cette joie d'écrire ne va pas de soi, elle se doit d'être conquise dans la confrontation à un sujet qui requiert, telle une condition sine qua non, d'y être impliqué émotionnellement. C'est comme partir d'un inconfort pour y créer son confort, là où le tourment parvient à rire de lui-même. C'est ce que je dis à ma grand-mère, mais pas vraiment comme ça.

J'avais justement Pas pleurer dans mon sac, car je le parcourais pour un travail qu'on m'avait proposé. Je lui mets dans les mains, elle le retourne et commence à lire la quatrième de couverture, à voix haute, parce qu'elle a toujours aimé ça, lire, à voix haute. Quand elle a terminé elle dit oui, 
ah oui je vais le lire, et puis, comme si elle venait de se souvenir de quelque chose, elle redresse la tête, me regarde, David, tú quieres una fruta o algo ?, et en riant je dis non, esta bien, puis bois une gorgée de café. Alors qu'elle ouvre le livre au hasard des pages, lisant des bribes de lignes à droite à gauche, je commence à lui parler de ce que je ressens de très espagnol dans cette littérature, et j'en reviens à évoquer le registre de langue, à cette oralité qui permet d'aller au plus près du parler des personnages, de leurs expressions, et de procéder à ce métissage linguistique si juste, si sonore, si ambivalent également, quand la langue littéraire rencontre le parler ordinaire, le langage de la rue, sans opposition, sans artifice non plus, simplement dans une grande maîtrise de ce que l'un peut apporter à l'autre. Ça donne quelque chose de sonore et de proprement jubilatoire. Quelque part, et alors qu'on pourrait y voir une manière de rejeter le classicisme en littérature, en vérité on le renforce, on le pérennise, en le nourrissant, en le renouvellant et l'enrichissant de tournures qui, plutôt que de s'y substituer, s'y greffent. Alors forcément, Lydie Salvayre ne fait pas l'économie de l'argot, ni même de la vulgarité, encore que chacun est libre d'appeler ça comme il le souhaite. Elle est d'accord avec moi, ma grand-mère, quand je dis que le mot « vulgarité » c'est pour les fragiles. Nous, on appelle ça la « familiarité », parce que la vulgarité on la voit davantage dans des attitudes, des idées, des postures, que des mots. Ce rapport désinhibé à la langue familière donc, franc et joyeux, capable d'inventions perpétuelles, suppose un rapport indéfectible à l'incarnation en littérature, car on ne peut faire l'économie du réel si l'on veut montrer, de manière authentique et véridique, un univers, et les gens qui le composent. Et ce rapport à la langue infuse bien au-delà de l'espagnol dans l'œuvre de Salvayre, qui toujours cherche à se placer à la frontière, qu'il s'agisse 
de celle qui sépare l'éthique de l'esthétique, ou bien celle entre le bon et le mauvais goût, entre l'oralité et l'écriture, ou bien encore celle qui prétendrait séparer la littérature du réel. Je bois la dernière gorgée de café, puis éteins ma cigarette dans le cendrier. Je parle du sens de l'équilibre, que je trouve admirable, chez Salvayre. L'usage de l'ironie, s'il peut être une pudeur, n'en reste pas moins une opportunité esthétique. C'est grâce à elle qu'elle arrive à jongler entre le grave et le léger sans jamais que ça jure. Ainsi l'impudeur n'a rien d'obscène. Parce que l'imperfection est acceptée d'emblée, dans le fond comme dans la forme, et on y reconnaît la vie, ambivalente et paradoxale, comme son écriture, perméable et poreuse, sujette à la circulation des registres, et s'érigeant presque contre toute conformité littéraire. Même la structure de ses livres ne prétend à aucune standardisation, au contraire, dans Pas pleurer on a plusieurs étages de narration et pourtant on s'affranchit de toute construction logique du récit, les histoires se mêlent et s'entrechoquent de la même manière qu'ont les souvenirs de surgir, cette manière foutraque comme un ricochet cérébral, qui implique que les enchaînements n'aient pas forcément de logique intellectuelle sinon émotionnelle, en ce sens que l'on progresse bien d'un sentiment, d'une sensation à l'autre, plutôt que d'un concept, d'une idée à l'autre, comme on le ferait dans un écrit explicatif, raisonné et ordonné, ce à quoi ne peuvent être sujets les récits de vie. La littérature de Salvayre n'est pas une représentation de la vie, mais bien la vie incarnée en texte, là où l'encre et le papier deviennent chair et os. Et je dis ça à ma grand-mère, en espérant qu'elle m'écoute encore, qu'elle comprendra où je veux finalement en venir à lui parler de tout ça, et je lui dis donc que pour moi la grande qualité de Lydie Salvayre c'est cette manière qu'elle a de ne pas écrire sur, de ne pas faire reposer la force 
de son texte sur son sujet mais bien dans une langue qui le servira, et donc d'écrire dans, d'écrire depuis, et qu'au final, mon sentiment dominant quand je lis ou bien évoque son écriture, c'est que moi aussi, j'ai envie d'écrire, que la lire me donne envie d'écrire, et ma grand-mère est satisfaite, quand elle entend ça.

On ne peut plus regarder la montagne en face sans être ébloui par le soleil mais on le fait quand même. Une autre cigarette, près de la fenêtre cette fois, pour sentir l'air. Elle va allumer l'écran, mettre le son très bas, et je vais m'allonger pour la sieste. Mais avant cela, je reste pensif quelques secondes, en regardant le siège de mon grand-père, tourné vers la montagne. 


\section{Marie Cosnay}

\section{Diamant brut}

Ce coup de fil, au petit matin. Le coup de fil porte les ingrédients d'une histoire. Au cœur de l'histoire racontée au téléphone, une enfant. D'Irun, Poitiers et Bruxelles, chacun dans sa chambre ou cuisine du petit déjeuner, nous sommes projetés, par ondes électromagnétiques, au cœur de l'histoire dans laquelle il y a, comme protagoniste principale, une enfant, 15 ans, venue de Conakry. D'Irun on nous dit, au téléphone : un ange, une perle, un diamant, on ajoute : brut. Un diamant brut.

Le diamant brut avait quitté son pays pour en remonter d'autres, territoires après territoires, territoires sans nom et sans spécificité sinon du point de vue des plus ou moins grands dangers qu'on y rencontrerait, ici le viol, ici le feu du soleil, là les policiers jetant des pierres, la noyade, les centres, puis le vide total parce qu'il n'y a plus de route. La route, c'est fini, Espagne France Belgique Allemagne et demi-tour. Europe est une terre avant une autre terre, mais il n'y a pas d'autre terre, Europe n'est qu'une étape avant un but mais il n'y a pas d'autre but. On est arrivé à la fin et on tourne dans la fin comme dans une cage.

Published in Lydie Salvayre, maintenant même, ed. Warren Motte (Lincoln, NE : Zea Books, 2021). doi: 10.32873/unl.dc.zea.1288 
L'enfant, 15 ans, le diamant brut, appelle au secours. Appelle Irun au secours parce qu'Irun a croisé sa route et Irun au petit matin appelle à son tour au secours. Le diamant brut ne sait pas dans quel pays elle est arrivée, y est arrivée avec deux adultes qui ont disparu voici trois jours. Le diamant brut, dite l'ange à Irun, est enfermée dans une pièce dont elle n'a pas la clef, si elle sort ne rentrera plus, les adultes parents ont disparu, le pays sans nom d'Europe les a mangés. Irun géolocalise l'enfant par téléphone portable, voici l'adresse, porte de Namur, Ixelles. La rue, de tel à tel numéro. Belgique donc. Irun dépêche des éclaireurs de Belgique contactés de Poitiers, les éclaireurs de Belgique crient, dans la rue, aux fenêtres, le prénom du diamant angélique. L'enfant fermée ou dedans ou dehors, pas de passage possible dans un pays qui n'a pas de nom et ne permet, puisqu'on est arrivé, lui non plus, aucun passage. Le piège, et la panique. D'Irun à Poitiers à Ixelles on se fait passer l'histoire à trous, on a très peu de choses pour ravauder les trous, on fait avec le très peu, on ajoute des éléments, des hypothèses, les éléments-hypothèses débordent l'histoire, par le bas, par le haut, c'est l'endroit fourmillant de la croissance des histoires et on est, Irun, Poitiers et Ixelles, heureux de la croissance fourmillante des histoires parce qu'on sait que jamais aucune histoire n'est une somme chronologique stricte de personnages, psychologies, d'accidents.

Tout ce monde, d'autres encore, autour d'une enfant passée à Irun, accompagnée de cousin cousine, tout ce monde, malgré les éléments chaotiques de l'histoire, autour d'une enfant qui est un ange, un diamant brut, toutes ces mains, ces oreilles et ces bouches, d'Irun à Ixelles, pour faire passer, écouter, pour comprendre-et pour joyeusement ne pas comprendre. Tu as ici les continents, les mers, les dieux 
et les forces contraires, tu as ici les empêchements, les flots vagues flux toutes les grimaces et tu as une personne, pas un flot de personnes, une personne, une perle précieuse, comme on dit à Irun, suivie d'ici à là, suivie sauvée par un groupe de personnes qui ne se connaissent pas mais suivent sauvent ensemble, sauvent une personne, ouvrent les portes, rusent avec les portes, tu sais, ces petites cales qu'on peut coincer dedans pour ouvrir quand on ne peut plus ouvrir. Toutes, qui suivent sauvent ensemble, un, une, chacun, chacune.

Dans le village que je connais, quand les jeunes sont venus en répit, comme on disait alors, le cafetier du village était contre. On raconte qu'il tenait au début des propos dignes de ceux de Marcelin de Barogne. Le cafetier du village que je connais n'a jamais refusé de servir qui que ce soit mais il constatait et faisait constater qu'il n'était pas prêt à s'enrichir, avec ces gars-là. Les copains et les copines, tout le monde, disait-il, étaient allé.e.s les aider. On n'imaginait pas du tout capable le cafetier de ce village de formuler les choses très ordurières que disent Dédé, Émile et les copains, dans Tout homme est une nuit.

Ni s'emporter comme ils le font.

T'emporter seul, pendant que les copains vont aider?

On aurait dit qu'il en avait une fierté par procuration, de ses copains et copines qui étaient allé.e.s aider. Peut-être n'osait-il pas, devant nous, formuler autre chose mais ce n'était pas si mal qu'il n'ose pas. Si souvent on se met en tête de ressembler aux choses qu'on dit, comme si on pouvait s'y résumer.

Le cafetier, dans le village que je connais, disait que tout le monde avait aidé et que bah, à part la pêche, bien sûr (ils attrapent les truites quand c'est pas le moment), ils sont pas si différents, au fond. 
À quoi ça tient?

À très peu, aux copains et copines qui ont aidé, à ces filles qui posent la question après coup et qui ont l'air de trouver génial ce qui s'est passé au village.

Et les actes tiennent un peu aux discours qu'on tient.

À Barogne, les propos dégueulasses sont suivis d'une chasse à l'homme.

Mais ni dans ses discours ni dans ses actes, on n'est tout entier.

Le cafetier de Barogne, Marcelin, n'est pas que ce qu'il a l'air d'être.

Il n'est pas que les discours de haine qu'il tient.

Il n'est pas que ses actes.

Il est aussi le père d'Augustin.

Cette jeune fille de quinze ans s'est mise, au village, à pleurer à chaudes larmes devant les hôtes du Soudan et d'Erythrée.

Elle les voit, elle pleure.

Son père dit qu'elle a peur.

Elle n'a jamais vu de noirs, alors elle a peur.

Elle-même dit qu'elle a peur, elle dit que c'est la raison de ses larmes.

Le mot peur en enferme d'autres.

Du trop, du trop grand, le monde, un monde?

Un jeune homme que je connais, plein d'arguments et de joie, accueille ces jeunes de son âge. Il écoute les longues routes, les parcours tortueux, les aberrations. Après quelques jours il découvre sur son corps des manifestations cutanées inhabituelles, une sorte d'eczéma.

C'est rien, dit le médecin-en effet le symptôme cutané guérit dans la nuit.

Le jeune homme dit : je ne suis plus le même. 
Je change, tu vois, je change de peau.

Il y a le désir de n'être pas tout à fait le même, on peut ne pas le savoir et moins on le sait, plus le désir est accompagné de peurs, de symptômes.

Marcelin et Dédé n'ont pas envie de changer de peau.

Certainement, Lydie Salvayre le suggère, ils ont trop peur.

Au village, chez nous, dans plein de villages, dans de plus en plus de villes et villages, des hommes et des femmes, des familles entières, sont accueillies dans d'autres familles.

Aux réunions, les personnes viennent avec leurs questions et leurs peurs. Mais quelles sont leurs peurs ? Légalité ou pas. Mon métier ou pas. Ma maison ou pas. Plus d'une semaine, je ne peux pas. Or, je ne mettrai personne dehors. Que faire donc à la fin de la semaine? Moi, je dirais un mois. Que faire après un mois ? C'était une question morale. Si je ne fais pas c'est par peur de ne pas faire assez. Ce qui en retenait quelques-uns, c'était la question morale qu'il y avait tant à faire, qu'on devait le faire jusqu'au bout. C'était un devoir moral, humain. Les devoirs moraux, humains, ne s'arrêtent pas en chemin.

Le lien humain, ce truc qui s'est brisé dans le roman de Lydie Salvayre, ce truc brisé qui fait que Jacques préférerait quitter le village pour vivre dans une cabane, à la Thoreau.

Les jours de réunion, on laisse vivre des espaces doucement flous. On se dépatouille bien. Augustin se dépatouille bien dans le roman : il parle. Il passe par-dessus l'inhumanité, en parlant. 
Quand Martine a appelé avant la fin de la première semaine : le garçon est adorable. Mais il va mal, il a passé toute sa vie dans des camps, il ne dort pas, du coup je ne dors pas. Il ne comprend aucune langue, ni l'anglais ni l'arabe. Il fait ses prières. C'est un homme. Je suis une femme. Vite, trouver un relai, pour que Martine dans cette histoire ne se sente jamais plus fragile qu'elle ne peut le supporter, qu'elle ne se sente jamais fragile comme Dédé, Émile ou Marcelin.

Dire : on fait avec et à partir de notre impuissance, notre immense impuissance.

Notre impuissance à consoler, notre impuissance à nous consoler nous-mêmes.

Dire : il faut supporter notre impuissance. Faire quand même. C'est ainsi qu'on ne deviendra pas ce qu'on peut toujours devenir, l'Histoire le sait-les personnages de Tout homme est une nuit aussi. 


\section{À propos de Lydie Salvayre}

Cher Professeur Notte,

Vous noterez que je continue à buter sur votre patronyme. Allez savoir pourquoi ma mémoire n'a pas enregistré Motte. Allez comprendre le fonctionne du cerveau. Vous en savez quelque chose vous? Moi non ? Il faudrait demander à Lydie Salvayre. Vous ne pensez pas ? La fille a exercé comme psychiatre. La tronche, la caboche, elle connaît, pendant plus de trente ans, elle a nagé dans les délires et les névroses. Et ? Donc? De quoi je parle? J'y viens, cher Professeur. Patience. Faisons à la Française. D'abord, les politesses.

Un grand, un immense, un interstellaire merci, cher Professeur pour l'honneur que vous me faites en me proposant de rédiger un article de 2.000 mots « Sur l'écriture de Lydie Salvayre ». Moi petit homme de trente-deux ans qui sait à peine écrire. Qui avait à peine lu Lydie Salvayre avant votre proposition. Juste son Pas pleurer, parce que Goncourt, surtout parce que Guerre d'Espagne, aussi parce que parents réfugiés, parce que moi avoir histoire similaire, mais d'un autre pays, à une autre époque, et parce que dans la lecture, on cherche aussi un peu de soi-même. J'ai en mémoire de m'être senti en terrain connu dès les premières pages.

Published in Lydie Salvayre, maintenant même, ed. Warren Motte (Lincoln, NE : Zea Books, 2021). doi: 10.32873/unl.dc.zea.1289 
Quelque part comme chez moi, par le rapport à la mère, à la langue, au déracinement, à l'amour de la littérature, mais chut ! Je vais y revenir. Quatre ans plus tard, grâce à votre cadeau divin, à votre offre du diable, à votre proposition que je ne pouvais pas refuser, me voici à tenter de commander chez une libraire allemande d'Hambourg, une grande partie de l'œuvre de Lydie Salvayre. Lydie was? Was haben Sie gesagt? Salvaro ? Kenne ich nicht ... Sie hat ein Goncourt gewonnen! Oh, wie schön!

Pourtant Madame la libraire allemande du Bücherstube de la Rothenbaumchaussee à Hambourg, la Docteure Salvayre est l'une des voix majeures de la littérature française contemporaine. Elle pèse sur le game, comme diraient les jeunes. On l'invite sur les plateaux télé pour parler des livres des autres. D'après elle, elle s'en sort mieux que pour ses propres livres, parce que selon elle, elle se débrouille mal à l'oral. Faux Docteure Salvayre, laissez votre modestie tranquille au chaud dans votre aire de Broca. À l'inverse de l'essentiel des Français, la Docteure Salvayre parle comme elle écrit, c'est précis, juste, économe, sans faute, elle ne snobe jamais, flatte l'intelligence, n'envoie pas cinquantedouze références au visage pour démontrer son art, mais juste quelques-unes, utiles à sa narration, qui permettent de s'érudir. S'érudir? Je viens de chercher le mot. Introuvable. Je viens de lire sur le forum de languefrançaise.net que les dictionnaires français ne l'auraient pas référencé.

Constatez par vous-même. 
Sujet : Un mot pour désigner le fait de devenir plus intelligent, plus cultivé.

par Abouricha

Réponse de papy à 18-09-2010 à 00:08

« Cher Abouricha, j'ai pensé à s'intelligenter. Mais le mot fait un peu trop barbare à l'oreille, on sentirait tout de suite que c'est une invention de mon cru.

Le verbe s'érudir que DB propose est pourtant très intéressant, il convient tout à fait à ce que vous cherchez, mais quel dommage que le mot n'existe pas ».

S'érudir donc. Notez-le cher Professeur. Il est pas mal ce mot non ? Vous me demandiez comment écrit Lydie Salvayre, je vous sers une réponse sur un plateau. Elle invente des mots, des trouvailles, des perles compréhensibles par elles-mêmes ou par le sens de la phrase. Lire Lydie, c'est autant voyager dans la langue que par le récit. Sans me lancer dans une psychanalyse littéraire, pour laquelle le talent me manque davantage encore que pour la critique, je dirais, en comparant la vie du Docteure Salvayre à la mienne, que son goût immodéré et insolent pour le tripotage des mots provient de sa double culture. Cela doit venir de la madre. De sa daronne. Ouvrez Pas pleurer et enjaillez-vous à découvrir Madame Montse Arjona, sa mère, faire danser le hip-hop à la langue française sur un fond de flamenco. Maintenant, prenez une respiration, réfléchissez, vous êtes enfant, dans les années cinquante, dix ans après une terrible guerre, dans un pays en construction, vous allez à l'école de la République française, bien élitiste, où l'on vous chahute les oreilles, et même les doigts, si vous accordez un participe passé avec le verbe avoir. De retour à la maison, votre madre, votre maman, votre mère, votre matrice, la source, l'origine de votre 
vie, vous chérit dans un français estropié, bassiné d'espagnol, tout en vous sermonnant d'étudier avec sérieux. Vous êtes balancé dans un canyon entre deux cultures. Plus tard, vous en riez. Et pour la vie, vous nagerez d'une rive à l'autre. Paraît-il que les enfants grandissant avec plusieurs langues sont plus vifs ? En relisant ma chronique, je ne peux que constater la véracité du propos. Ahlalala ! Je vous vois déjà tousser cher Professeur Motte devant ce manque flagrant de modestie. Détrompez-vous, voici une dose d'ironie bien française, omniprésente dans l'œuvre du Docteure Salvayre. Quelle dextérité dans le maniement de l'ironie, que ce soit dans les premiers livres, comme dans La Vie commune, où une vieille chef de publicité souffre de l'arrivée d'une nouvelle secrétaire au bureau, au point d'en dresser un portrait démoniaque, ou dans $B W$, le récit de la vie d'un homme que la Docteure Salvayre connaît trop pour ne pas l'abîmer. Toujours avec humour et amour. Mais nous y reviendrons.

La moitié de ses personnages sont un peu, ou beaucoup, désorientés. Des pommés, des perdus, des frappés du crâne, souvent dans l'adversité. Elle a travaillé plus de cinq ans, de nuit, dans une clinique psychiatrique. Et je me questionne, est-ce qu'un psychiatre est aussi malade que ces patients? A-t-elle trop pratiqué au point de se contaminer ? Faut-il être fou pour écrire? Pour passer des heures à raconter sa vie ou celles des autres? Pourquoi Docteure Salvayre? Pourquoi écrivez-vous ? Elle me donnera la réponse un vendredi soir à dix-huit heures, du fin fond de sa campagne, alors que mes voisins allemands m'attendent pour boire un Glühwein de Noël.

« Une colère cher ami. Une grande colère. J'étais jeune. Invitée dans une soirée chez des bourgeois. Je pensais y 
apprendre des choses, en tirer enseignement. Un grand type m'a dévisagé en me décrivant comme "cette fille qui fait bien modeste". Tu vois à quoi cela tient. Il m'a piquée et j'ai voulu, je ne sais pas ce que j'ai voulu. Mais je crois que tout a démarré là ».

La pulsion. La pulsion de vivre. Docteure Salvayre porte la plume dans la plaie, dans ses plaies, celles du monde, dans ses déchirures, ses meilleurs livres sont écrits avec le cœur fendu, avec la hâte de vouloir le réparer. Un soir, dans le sud de la France, en croquant une crevette, pendant un festival littéraire, alors qu'elle m'écoutait avec une patience de médecin, soudain, elle me fait remarquer que les grands écrivains ont un problème de père, me citant Mann et d'autres. Moi j'ai cherché son père dans ses livres, la mère est là, le père est amoché, plus tard, elle me confiera qu'avec le padre la vie était dure.

À présent, je voudrais aborder un point essentiel de l'écriture de la Docteure Salvayre. Son humanisme. Ses personnages ne sont ni gentils, ni méchants, ni bons, ni salauds. Ils vivent avec défauts, colères, paradoxes. La Docteure Salvayre sait lire. Sait lire dans l'humain, dans la passion et dans la raison, elle nous raconte Bernanos découvrant les horreurs de la guerre d'Espagne, elle prend un camp, celui de l'âme humaine dépassée face à la grande Histoire. Dans La Puissance des mouches, encore un homme, que nous autres humains sans éclat présumons fou, discourt sur son crime. Sur ses raisons. Sur sa trajectoire de vie. La Docteure excelle dans le tête-à-tête, elle triture, et fouille, regarde, ausculte, détaille, nous permet d'établir le diagnostic. Il y a de la compassion. Une immense compassion, quand elle expose les traumatismes et les souffrances de ses héros. Pendant des 
années, dans son bureau, elle a écouté ses patients. Elle s'est interrogée pour les soigner, a accumulé les parcours dans son Hippocampe pour les transformer en une matière première de son œuvre. Elle a aidé ses patients à retrouver leur pleine joie de vivre, l'envie de continuer, leur liberté.

La liberté. Venons-y. Elle est partout, transpire dans chaque livre. Les héros veulent vivre. Et elle rend hommage à leur envie d'embrasser cette liberté. Elle transpire aussi dans les thèmes, et notamment dans ce regard féminin libre et sans concession sur les hommes s'emparant des femmes, de leur sexe. D'ailleurs chez la Docteure Salvayre, je lis un féminisme revendiqué. J'en suis heureux. Elle défend les femmes sans jurer à la fin des hommes. Elle leur donne une voix. Elle pose le masculin sur la balance, laisse l'aiguille monter, ficelle le sachet, le livre au lecteur avec une immense indépendance. Elle n'a pas peur. Elle n'a pas de complexes. Elle est médecin. Et croyez-moi, Professeur Notte, j'ai quelques médecins du côté de ma belle-famille, quatre exactement, et on se marre bien. Aucun complexe, ils savent se rire de tout, d'eux-mêmes, de la vie et des patients. Pour un bon médecin, la vie est tout et elle n'est rien. Elle n'a pas de prix. La vie est le métronome. La vérité. Et pour y survivre, la légèreté est de rigueur. Il est de notoriété publique, que nos médecins français, pendant leur formation à l'internat, se prêtent à toute une série de jeux puérils dignes d'enfants sadiques. Les Français nomment cela l'esprit cabotin, et nous excusons nos bons docteurs, parce qu'ils nous soignent, et aussi parce qu'ils peuvent devenir de bons écrivains. Le métier demande rigueur et précision, chez la Docteure Salvayre, l'écriture témoigne de ces qualités. La psychiatre lit dans la douleur pour dessiner la vérité. Avec l'humilité de ceux qui ont accédé au grand monde 
par le seul mérite de leurs études. Lydie vient d'un milieu populaire, de parents ayant fui la guerre d'Espagne réfugiés en France. C'est un directeur de cours complémentaire, une école pour jeune fille se destinant à être femme au foyer, qui la repérera et la poussera à aller au lycée. La suite, nous la connaissons.

Continuons. Le Petit Traité d'éducation lubrique. Voilà un autre petit livre parfumé de liberté qui raconte l'intimité avec drôlerie. Au moment de sa republication il y a deux ans, j'ai entendu, autour de moi, surtout de la part de jeunes critiques littéraires, des mots d'incompréhension face à ce livre. Professeur Motte, vous vous rendez compte, des jeunes de trente ans, étonnés, pardon, choqués, interdits, ahuris, de découvrir le propos de ce petit livre. Et nous qui pensions que l'époque était à la liberté sexuelle ? L'est-elle vraiment ? Ce n'est pas à moi de savoir, ni de le dire, mais Lydie vous répondrait que oui, qu'avant, on était plus libres, qu'on faisait plus en disant moins, et c'est ce que j'ai cru lire à travers ses lignes. Notamment quand elle raconte l'adolescence espagnole de sa mère.

Venons-y. L'Espagne. Inutile de vous dire que la Docteure Salvayre est malade d'Espagne. De sa langue. Ses histoires sont peuplées de Don Quichotte, un coup, c'est un père, l'autre, c'est une femme de ménage, ou un gardien d'immeuble, des personnages méditerranéens tantôt loufoques, toujours colériques, passionnés, emportés, comme dans sa famille, je crois savoir. Lydie Salvayre semble nous dire que tout comme nous portons le patrimoine génétique de nos parents, nous portons également le patrimoine mémoriel de notre famille. 
Et si je peux me permettre de parler de mon expérience, je comprends cette passion. Je suis né 39 ans après la Docteure Salvayre, dans la même France mais plus vieille. Dans la mienne, on ne m'a jamais dit franchement, mais suggéré habilement d'oublier ma culture familiale pour épouser celle de la terre d'accueil. Était-ce la même pour la Docteure Salvayre ? Si bien qu'à l'âge de ses premiers faits d'armes littéraires, munis de sa formation de spéléologue de l'âme humaine, elle a voulu rattraper le temps perdu. Boire ce lait maternel. Le célébrer. Le magnifier. Nous donner envie de siroter un Tinto de verano, une San Miguel, un Rioja, un Cava, avec son Bernard, celui de BW sur une terrasse baignée de soleil à Valencia.

Bernard, quel homme et quel amour pour cet homme, vous ne trouvez pas Professeur Motte? Quel homme ne rêverait pas d'être ainsi aimé ? Voir sa vie, ses exploits, son intelligence, son tempérament célébré dans un livre. Le meilleur pour moi. Le plus vif. Le plus fort. Peut-être parce que $B W$ raconte en partie un monde que je connais ? Celui de l'édition parisienne. Peut-être parce que dans chacun de nous, il y a un peu de ce Bernard ombrageux, tenu en laisse pour permettre le processus de civilisation. Il est éditeur. Il la lit. La relit. La corrige. Et elle l'aime de son grand amour. Je dirais, je m'avancerais à dire, que derrière cette grande auteure qu'est Lydie Salvayre, il y a un homme discret au grand cœur, nommé Bernard Wallet. Un homme conscient infoutu de digérer la saloperie du monde, un écorché vif, trimballant sa carcasse à corazón ouvert. Comme la Docteure Salvayre.

Elle se soucie du monde, de l'époque, de la nuit qui pourrait tomber, de l'hiver qui avance, elle m'a murmuré ne pas être entièrement satisfaite de son dernier, Tout homme est 
une nuit, je n'étais pas d'accord, ce n'était pas pour la flatter. Je l'ai trouvé mieux que d'autres. Professeur, vous lirez, vous avez lu ce que la France devient, ce que d'un côté les urbains deviennent et de l'autre les campagnards. Vous lirez ce que nous autres Français, avons aimé et chéri, la campagne et l'esprit campagnard, ont dépéri à cause de l'ignorance, l'oubli, le snobisme des gens des grandes villes. Vous lirez ce monde qui glisse, qui peu à peu a pris le parti de détester le monde qui pense et qui lit. Peut-être à raison, parce que ce monde n'a pas voulu accorder le respect qu'il se doit aux peuples des campagnes.

Un dernier point central, cher Professeur Notte ou Motte ou je ne sais quoi. Ne vous enfuyez pas, et excusez mon arrogance tout à fait française. Comme tout bon converti-j'ai obtenu la nationalité française à l'âge de treize ans-, je suis plus royaliste que le roi. Je serai bref. Un dernier point central, la solitude. Cette impression permanente que ses personnages vivent au milieu d'un océan de voix, d'esprit. Qu'ils crient sans être entendus. De ma lecture vorace de ses livres, je crois comprendre que la grande énigme de son œuvre est la solitude. Que peut faire l'être humain face au monde? C'est la question qu'elle semble nous poser livre après livre.

Voilà cher Professeur Motte, ce que je peux dire de l'écriture de Lydie Salvayre. Vous m'avez lancé un sacré défi, celui de lire l'œuvre complète d'un auteur. Périple littéraire auquel je ne m'étais adonné jusqu'alors. Voici comment plonger en quelqu'un. Le voir évoluer. Serrer sa plume. Affuter sa pensée. Dérouler son âme. Son style m'habite à présent, au point que je ne sais plus écrire autrement. Je vais vous faire une confidence. J'ai connu la Docteure Salvayre sur un plateau de télévision. Elle était dans ma diagonale, je 
portais une veste à motif africain, on s'est échangé un regard, puis deux, puis dix, et immédiatement j'ai été frappé d'un coup de foudre d'amour d'amitié. Tout était dans le regard. Vous connaissez cette sensation? Ah oui ? Avec votre chien? Soit pourquoi pas. Dans les mois suivants, nous avons fait connaissance. Rien à dire, à savoir de plus, je savais déjà tout. Je ne suis pas Professeur de littérature, tout juste auteur d'un roman, certes anobli par l'académie Goncourt, juste un lecteur. Un grand lecteur qui par le hasard de la vie a connu quelques écrivains à un âge relativement jeune. Et je peux vous dire, vous assurer, qu'il n'y a que deux catégories d'auteurs, les mauvais et les bons, que leurs livres racontent autant leurs histoires qu'ils décrivent leur intelligence littéraire. L'auteur et son œuvre font corps. Regardez Lydie. Arrêtez-vous un instant. C'est ce que j'ai fait la première fois. Précise, profonde, douce et dure car vraie, toujours bienveillante. Je n'ai rien appris de plus dans ses livres. Lydie est dans la vie comme dans ses livres. Elle ne ment pas. Ne triche pas. Lydie c'est la vérité. 


\section{Stéphane Bikialo}

\section{Éloge de la fuite}

[Ce texte a paru dans Lydie Salvayre, éd. Stéphane Bikialo, Classiques Garnier, 2020.]

«Si on y allait? »

(fin de $B W$ )

Je pars.

Toujours il dit Je pars, je me tire.

Il aime le mouvement de partir. Il se fout de l'endroit à atteindre, ce qu'il aime c'est partir, c'est déclarer qu'il part. Il dit qu'il va écrire, un jour, l'éloge de la fuite. $(B W)$

C'est BW qui le dit, et c'est Lydie Salvayre qui l'écrit, inaugurant avec cet ouvrage, paru en 2009, une série qu'elle décrira ainsi dans Hymne (2011) : « le temps presse et [...] il me faut aller désormais vers ce qui, entre tout, m'émeut et m'affermit, vers tout ce qui m'augmente ». Ce sera les 7 femmes en 2013, et sa mère et Bernanos en 2014 avec Pas pleurer, roman dont j'emprunterai le dispositif énonciatif

Published in Lydie Salvayre, maintenant même, ed. Warren Motte (Lincoln, NE : Zea Books, 2021). doi: 10.32873/unl.dc.zea.1290 
d'ouverture («C'est Bernanos qui le dit ») afin de suivre cet « éloge de la fuite » qui s'écrit dans l'œuvre de Lydie Salvayre, d'un roman à l'autre, d'une fuite à l'autre. Et cet éloge de la fuite, j'ai eu envie de l'écrire avec les personnages de ses livres, avec BW en particulier car tout le livre est une variation sur le fait de partir, mais aussi avec Montaigne, « toujours botté et prêt à partir ». Souvent, chez Lydie Salvayre, il faut non seulement être prêt à partir, mais savoir partir, « car il faut des forces immenses pour s'élancer, contrairement à ce que postulent les assis qui assimilent la fuite à je ne sais quelle veulerie de l'âme » $(B W)$. Si en effet on peut partir pour le geste ou le mouvement même de partir, on peut aussi partir pour fuir, partir pour refuser, partir pour « disparaître de soi »...

Tout commence par « ce que pudiquement, on appela la Retirada » (Pas pleurer), qui fût à la fois une fuite et un refus : la fuite devant les violences commises par les franquistes, le refus de se soumettre aux fascistes triomphants. C'est ce que firent les parents de Lydie Salvayre quand l'Espagne devint franquiste. Cette fuite originelle est racontée dans Pas pleurer, mais aussi dans La Puissance des mouches et en arrière-plan de plusieurs autres romans (La Méthode Mila notamment). La fuite est aussi une solution pour signifier son refus de la société de la consommation et du spectacle contemporaine, comme y insiste Rémy Oudghiri dans Petit Éloge de la fuite hors du monde (Arléa, 2014) en prenant appui notamment sur la vie et l'œuvre de Pascal Quignard : «Au moment où le spectacle et la mise en scène de soi s'imposent comme des compétences centrales dans nos sociétés, le retrait du monde représente peut-être la dernière option pour ceux qui veulent protéger leur intimité ». C'est ce que fait la narratrice de Contre, qui décide de fuir après dix 
ans passés dans « une étrange république » où « les alcools sont fameux, ainsi que les fromages et l'esprit bien connu de collaboration $»$ :

Ma vie, je la portais comme on porte son sac.

Je sus qu'il fallait fuir.

Je pris les autoroutes. Je traversai des mers, des fleuves et quatre continents. J'avançais vite et sans me retourner. Comme on s'évade après un meurtre. Parfois, je fus tentée de renoncer à ce voyage et revenir à mon sommeil abject. Mais jamais, cependant, je ne relâchais mon rythme. Je voulais m'écarter d'un pays où les hommes s'éteignent à force de se soumettre.

Quand la vie devient survie, quand les semblables ne sont plus des frères, il faut savoir partir donc. Mieux vaut donc fuir, chercher un homme ou autre chose, que de se soumettre, que de rester dans un « sommeil abject », comme le fera la narratrice de Portrait de l'écrivain en animal domestique en se laissant anesthésier par le luxe prodigué par Tobold : « Je vivais dans une douceur soporifique que j'aurais réprouvée sévèrement six mois auparavant au nom des convictions politiques dont alors je me drapais ». Mieux vaut fuir que se laisser dominer par la «puissance des mouches » qui « empêchent notre âme d'agir » et « mangent notre corps » ( $L a$ Puissance des mouches). C'est le choix que font le narrateurpersonnage de Tout Homme est une nuit, Anas, et Mîna, car il leur est impossible d'habiter dans ce village où leur présence puis leur amour cristallise la haine : « habiter près d'une frontière, c'est plus commode pour s'enfuir » (dernière phrase du roman). Augustin, le fils de Marcelin le tenancier du café des sports, réussit lui aussi à partir (pas très loin certes) à la fois pour fuir et pour vivre. 
Partir, c'est ce que ne sont pas capables de faire les habitués du café des sports, sauf verbalement et ivres :

Émile, à demi assommé, se prit alors à hurler $\mathrm{Ah}$ ! putain ! si j'avais trente ans de moins, j'enverrais tout dinguer ! Tout ! Le pavillon qui m'a bouffé les économies de toute ma vie et que je n'ai pas fini de payer ! Tout, ma femme, les mioches, le garage, tout ce caca! hurla-t-il. Et j'irais faire la fiesta à Las Vegas ! [...] Moi aussi j'aimerais foutre le camp de chez moi, avoua Dédé, lui aussi bien éméché mais qui contrôlait encore.

Sans cette capacité à partir, à chercher autre chose, c'est le refus de l'autre qui émerge, comme Marcelin, Dédé et les autres, dont Montaigne aurait pu dire : «j'ai honte de voir nos hommes enivrés de cette sotte humeur de s'effaroucher des formes contraires aux leurs : il leur semble être hors de leur élément quand ils sont hors de leur village. Où qu'ils aillent, ils se tiennent à leurs façons, et abominent les étrangères » (Essais). Ce rejet de l'autre était déjà présent, en arrière-plan, dans La Méthode Mila, où les Roms, et Mila qui les soutient, cristallisent la haine des habitués du café des Ormes, ce qui aboutit au viol de Perline, la fille de Mila.

Lydie Salvayre montre à quel point les immobiles, ceux qui ne fuient pas car ils sont en position de pouvoir, sont bornés dans leur espace comme dans leur esprit. Ces personnages hiératiques, ce sont souvent des pères : le père de Josep et Montse puis Diego dans Pas pleurer tous les deux « DESPOTIQUES », le père du narrateur de La Puissance des mouches, etc. Ce sont aussi les puissants, ceux qui ont le pouvoir de l'argent : les dirigeants de La Médaille, Tobold dans Portrait de l'écrivain en animal domestique, l'huissier dans 
La Compagnie des spectres, qui ne voit pas plus loin que le bout de la loi. « Nous devons, quoiqu'il nous en coûte, nous cantonner à la Loi, disparaître derrière elle, être son ombre, rien de plus », recommande l'huissier en chef dans Quelques Conseils utiles aux élèves huissiers. Ceux-là ont les idées fixes et les mots morts comme dans La Médaille (« L'ouvrier vrai est modeste »; « Vivez votre travail dans sa dimension spirituelle ! »). Ceux-là font partir, expulsent comme ce même huissier, Maître Échinard, dans La Compagnie des spectres. Face à ces ennemis, il faut partir. Ou alors il faut les faire partir. Le narrateur de La Puissance des mouches fera le choix de tuer son père plutôt que de fuir, et Rose Mélie et Louisiane s'associeront pour chasser Maître Échinard à la fin du roman :

Avant d'ouvrir la porte, maman, doctement, déclara, citant Marcus Caton, Il faut faire avec le méchant comme avec l'ouragan le marin. Et sur ces belles paroles, nous le jetâmes dehors. Dans l'ouragan.

C'est la force ironique de Quelques Conseils utiles aux élèves huissiers que de donner des techniques (ne pas allumer la lumière, faire un concert de casseroles, invectiver son chat, bombarder de photographies au flash ...) pour faire partir ces réincarnations contemporaines des miliciens vichystes. L'huissier devient la figure emblématique de celui qui reste, qui poursuit son « inventaire du désastre » (premier titre envisagé pour La Compagnie des spectres) d'une maison à l'autre mais aussi d'une époque à l'autre, avec la rigidité de tous les réalistes, statiques, tièdes comme Descartes et sa méthode dénoncée dans La Méthode Mila.

Ces personnages aux corps et aux idées arrêtées sont souvent, quand ils ne sont pas dans la police (Passage à 
l'ennemie), les habitués des cafés qui déversent leur haine de l'autre, des étrangers, des nomades : ceux du café des sports (Tout Homme est une nuit), ceux du café des Ormes (La Méthode Mila), ceux du café des Platanes (La Puissance des mouches, La Compagnie des spectres). À la manière de Marie Cosnay dans Comment on expulse: Responsabilités en miettes, Lydie Salvayre restitue, d'un livre à l'autre, une chaîne de responsabilités de ce rejet de ceux qui sont partis et qui sont rejetés pour cela.

La fuite, le départ peut avoir plus nettement comme cause le refus. C'est Montaigne qui le dit : « l'autre cause qui me convie à ces promenades, c'est la disconvenance aux mœurs présentes de notre État » (Essais, livre III, chap. IX). C'est Josep cette fois qui le dit, et qui le fera avec Montse, sa sœur : « Je vais foutre le camp, dit-il, quitter ce trou à rat » (Pas pleurer). Quitter cette maison avec un père « facha » et ce village qui se laissera convaincre par le réalisme de Diego, c'est refuser la tiédeur révolutionnaire, la servitude volontaire des exploités et le cynisme des exploitants. C'est BW qui le dit et le fait aussi, son départ de la maison d'édition qu'il a créée étant aussi lié à son « horreur des ladres », à son refus de rester dans ce trou à rat que devient l'édition : «BW vomit la tiédeur et, par-dessus tout, la tiédeur littéraire », « car BW, qui est âgé de 62 ans a connu l'édition du temps où elle était, dit-il, une culture, une résistance ». Dans un entretien, Roland Barthes affirme que la seule contestation qu'aucun pouvoir ne tolère jamais, c'est « la contestation par le retrait. On peut affronter un pouvoir par attaque ou par défense ; mais le retrait, c'est ce qu'il y a de moins assimilable par une société » (« La crise du désir », repris dans Le Grain de la voix). Il faut donc savoir partir comme manière de dire NON, comme la narratrice de Contre, mais 
aussi comme l'Inspecteur Arjona, qui demande sa radiation, à la fin de Passage à l'ennemie, pour « partir » avec sa fiancée « quelque part, n'importe où, loin des familles et de leurs meurtres » pour se consacrer à Dulcinée mais aussi à « l'art d'écrire ». Celles-là ou ceux-là ne renoncent pas : en disant NON, ils disent aussi OUI, ils croient que ça mérite de partir, comme dirait Camus selon lequel l'homme révolté est « un homme qui dit non. Mais s'il refuse, il ne renonce pas : c'est aussi un homme qui dit oui, dès son premier mouvement » (L'Homme révolté).

La fuite se fait brusquement (« je me tire », dit BW ; «J'avançais vite et sans me retourner », lit-on dans Contre), elle est impulsive, elle est un élan, un saut hors de la rangée des assassins aurait dit Kafka. Le départ n'est pas le voyage, tout au moins pas un de ces voyages à la durée et aux espaces (escales, but) prédéterminés ; ainsi les personnages des Belles Âmes ne partent pas, ils voyagent, dans « les pourrissoirs de l'Europe » à la recherche moins du réel que de la réalité qu'ils ont observée à travers les médias. Ce sont des touristes, pas des « parteurs »-j'aurais bien employé « marcheurs » en référence aux travaux sur la marche de David Le Breton, mais il faudra d'abord désintoxiquer ce mot annexé par les macronistes en 2017-, auxquels il manque cette « humeur avide des choses nouvelles et inconnues » (Montaigne, Essais), comme Odile Coiffard qui se dit « fort déçue par ce qu'elle découvre. Ni voitures incendiées. Ni cabines téléphoniques saccagées. Ni tags sur les murs. Rien. $\mathrm{Qu}$ 'une trentaine de blocs ternes de part et d'autre d'une autoroute ».

Il est une forme de fuite qui ne se fait pas dans la rapidité (même si le départ peut être brusque) mais qui privilégie la lenteur : il s'agit de ce que l'anthropologue David Le 
Breton nomme « disparaître de soi » dans un ouvrage paru en 2015. Disparaître de soi, c'est faire l'expérience de la « blancheur », « cet état d'absence à soi plus ou moins prononcé, le fait de prendre congé de soi sous une forme ou sous une autre à cause de la difficulté ou de la pénibilité d'être soi » (Disparaître de soi). Par cette fuite ou disparition, il s'agit de refuser l'injonction très contemporaine à « être soi-même », injonction qui fige dans une identité comme Pascal Quignard le dénonce selon Rémy Oudghiri. Chez Lydie Salvayre, l'identité est toujours en doute (« je, qui ça? » trouve-t-on dans l'épigraphe empruntée à Beckett de Portrait de l'écrivain en animal domestique), car elle ne peint pas l'être mais peint le passage, « le vif du vivant » comme elle l'identifie chez Picasso. C'est pourquoi ses ouvrages abondent en formes de fuites hors du monde qui sont aussi des moyens de disparaître de soi : la lecture (de Pascal ou de Descartes par exemple), la folie (ou ce qui apparaît comme telle pour les autres) dans La Conférence de Cintegabelle, La Compagnie des spectres, La Puissance des mouches...

Tobold, suite à la découverte d'une inscription injurieuse à son égard, envisage de tout laisser tomber, de « disparaître de soi » :

Tobold était las de ce monde de merde, il me le confia d'une voix exténuée, il voulait vivre loin des banques de merde, loin des banquiers de merde et de leurs épouses de merde éprises d'art premier et de ce que, dans leur langue, elles appelaient littérature, il voulait vivre près des vaches de son enfance, crues et vivantes.

Mais Tobold n'atteindra pas la blancheur, il se reconvertira dans le charity business, ce qui lui permet tout à la fois de se construire une image de soi valorisante, de faire taire 
ses ennemis et de continuer son travail de domination par l'argent.

Disparaître de soi devient nécessaire dans une société où l'on est en permanence obligé d'être à la hauteur, où l'exigence d'être soi-même, dans sa cohérence, l'emporte sur le fait de l'être, dans sa diversité. BW rejoint les analyses de David Le Breton lorsqu'il « philosophile » :

Car vivre c'est quitter, pas d'autre issue pour l'homme, je cite la hagada, s'enflamme BW, passionné qu'il est des textes religieux. Car vivre c'est quitter père et mère et tout ce qui nous lie jusqu'à nous étrangler. Vivre c'est se quitter, c'est savoir être soi et échapper à soi, c'est savoir être soi et un autre que soi. (BW)

Le narrateur de La Puissance des mouches renonce à fuir mais parcourt des dizaines de kilomètres « le long des chemins de campagne » :

Je sors et prends le chemin qui mène à la forêt de chênes rouvres. Je marche longtemps. Je cherche un endroit sec. Je me couche sous un chêne. Je suis longtemps des yeux la course des nuages. Je ne pense à rien. Je me sens bien.

La marche est centrale dans de nombreux romans de Lydie Salvayre, notamment pour ces personnages qui ont besoin de « partir », ponctuellement ou définitivement. David Le Breton, dans un entretien au Temps (12 juillet 2016) au sujet de ses ouvrages sur la marche-Éloge de la marche en 2000, actualisé en 2012 sous le titre Marcher (éloge des chemins et de la lenteur) — souligne que « la marche est peutêtre la manière la plus démocratique pour retrouver des 
moments de paix, d'harmonie, de disparition de soi. Mais une disparition de soi mesurée. On part quelques heures ou quelques jours, et les portables ont souvent du mal à fonctionner dans les endroits isolés. L'immense succès sociologique de la marche tient à cette suspension des contraintes de l'identité. Sur les sentiers, plus personne ne sait qui vous êtes, vous n'avez de compte à rendre à personne. Vous marchez à votre rythme, vous vous arrêtez ... Personne ne vous rappelle à l'ordre pour un rendement que vous devez accomplir ». C'est ce que fait le narrateur de La Déclaration, qui « marche longtemps »: «j'espère fatiguer ma tristesse, m'oublier dans les jambes, me perdre dans le vert ». C'est ce que fait aussi le narrateur-personnage de Tout Homme est une nuit, quittant son lieu d'habitation et sa femme Lucile pour s'installer dans un village non nommé près de $\mathrm{Ba}-$ rogne-ne cherchez pas sur une carte mais sous le mot, pour y entendre la rogne et la bassesse-en raison de sa maladie :

$\mathrm{Au}$ lieu donc de m'amender, au lieu de me grandir, au lieu de me rendre aimable aux autres avant de définitivement leur faire mes adieux, la maladie distillait un poison dans mon cœur qui me faisait l'humeur amère et me rendait insupportable à Lucile comme à tous mes proches.

Pour toutes ces raisons-là, j'avais décidé de partir.

Partir, pour lui, c'est prendre rendez-vous avec soimême, c'est découvrir la forêt même à trente ans, « gagner en liberté » contre l'air vicié des méchants, mais aussi contre la sollicitude des proches. C'est aussi savoir se séparer de soi. Savoir partir c'est aussi savoir profiter de ce qui compte lorsqu'on a une maladie grave, et s'il faut finir, que ce soit en beauté : 
Je me disais que si la maladie l'emportait, je souhaitais qu'elle le fît en beauté, dans un lieu de beauté, dans un lieu d'éblouissante lumière, dans un lieu de profuses couleurs, dans le bleu le vert le rose et le lilas.

Je voulais bien finir avant d'appareiller vers l'ultime océan.

C'est le narrateur de Tout Homme est une nuit qui parle. Lui qui fera l'épreuve du fait que, comme l'écrit Éric Hazan dans Faire mouvement, « il est difficile de créer un îlot d'harmonie dans un océan de domination », lui qui réussit, comme de nombreux personnages de Lydie Salvayre, et comme elle-même depuis quelques années, réussit à se trouver une « arrière-boutique ». C'est Montaigne qui le dit : « il se faut réserver une arrière-boutique toute nôtre, toute franche, en laquelle nous établissons notre vraie liberté et principale retraite et solitude » (Essais, I, XXIX). 


\section{Ouvrages de Lydie Salvayre}

La Déclaration. Paris: Julliard, 1990. Paris: Verticales, 1997.

La Vie commune. Paris: Julliard, 1991. Paris: Verticales, 1999.

La Médaille. Paris: Seuil, 1993.

La Puissance des mouches. Paris: Seuil, 1995.

La Compagnie des spectres. Paris: Seuil, 1997.

Quelques Conseils utiles aux élèves huissiers. Paris: Verticales, 1997.

La Conférence de Cintegabelle. Paris: Seuil/Verticales, 1999.

Les Belles Âmes. Paris: Seuil, 2000.

Le Vif du vivant. Paris: Éditions Cercle d'Art, 2001.

Contre. Paris: Seuil/Verticales, 2002.

Et que les vers mangent le bœuf mort. Paris: Seuil/Verticales, 2002.

Passage à l'ennemie. Paris: Seuil, 2003.

La Méthode Mila. Paris Seuil, 2005.

Dis pas ça. Paris: Seuil/Verticales, 2006.

Published in Lydie Salvayre, maintenant même, ed. Warren Motte (Lincoln, NE : Zea Books, 2021). doi: 10.32873/unl.dc.zea.1291 
OUVRAGES DE LYDIE SALVAYRE

Portrait de l'écrivain en animal domestique. Paris: Seuil, 2007.

Petit Traité de l'éducation lubrique. Portiragnes: Cadex, 2008.

BW. Paris: Seuil, 2009.

Hymne. Paris: Seuil, 2011.

7 Femmes. Paris: Perrin, 2013.

Pas pleurer. Paris: Seuil, 2014.

Tout Homme est une nuit. Paris: Seuil, 2017.

Marcher jusqu'au soir. Paris: Stock, 2019. 
